\title{
Nudge strategies to improve healthcare providers' implementation of evidence- based guidelines, policies and practices: a systematic review of trials included within Cochrane systematic reviews
}

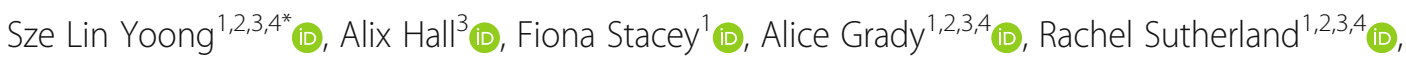
Rebecca Wyse ${ }^{1,2,3,4}$ (D) Amy Anderson ${ }^{2,3}$ (D), Nicole Nathan ${ }^{1,2,3,4}$ (D) and Luke Wolfenden ${ }^{1,2,3,4}$ (D)

\begin{abstract}
Background: Nudge interventions are those that seek to modify the social and physical environment to enhance capacity for subconscious behaviours that align with the intrinsic values of an individual, without actively restricting options. This study sought to describe the application and effects of nudge strategies on clinician implementation of health-related guidelines, policies and practices within studies included in relevant Cochrane systematic reviews.

Methods: As there is varied terminology used to describe nudge, this study examined studies within relevant systematic reviews. A two-stage screening process was undertaken where, firstly, all systematic reviews published in the Cochrane Library between 2016 and 2018 were screened to identify reviews that included quantitative studies to improve implementation of guidelines among healthcare providers. Secondly, individual studies within relevant systematic reviews were included if they were (i) randomised controlled trials (RCTs), (ii) included a nudge strategy in at least one intervention arm, and (iii) explicitly aimed to improve clinician implementation behaviour. We categorised nudge strategies into priming, salience and affect, default, incentives, commitment and ego, and norms and messenger based on the Mindspace framework.

Synthesis: The number and percentage of trials using each nudge strategy was calculated. Due to substantial heterogeneity, we did not undertake a meta-analysis. Instead, we calculated within-study point estimates and 95\% confidence intervals, and used a vote-counting approach to explore effects.

(Continued on next page)
\end{abstract}

\footnotetext{
* Correspondence: serene.yoong@health.nsw.gov.au

${ }^{1}$ Hunter New England Population Health, University of Newcastle, Locked

Bag 10, Wallsend, New South Wales 2287, Australia

${ }^{2}$ School of Medicine and Public Health, The University of Newcastle,

Callaghan, New South Wales 2308, Australia

Full list of author information is available at the end of the article
}

(c) The Author(s). 2020 Open Access This article is licensed under a Creative Commons Attribution 4.0 International License, which permits use, sharing, adaptation, distribution and reproduction in any medium or format, as long as you give appropriate credit to the original author(s) and the source, provide a link to the Creative Commons licence, and indicate if changes were made. The images or other third party material in this article are included in the article's Creative Commons licence, unless indicated otherwise in a credit line to the material. If material is not included in the article's Creative Commons licence and your intended use is not permitted by statutory regulation or exceeds the permitted use, you will need to obtain permission directly from the copyright holder. To view a copy of this licence, visit http://creativecommons.org/licenses/by/4.0/ The Creative Commons Public Domain Dedication waiver (http://creativecommons.org/publicdomain/zero/1.0/) applies to the data made available in this article, unless otherwise stated in a credit line to the data. 
(Continued from previous page)

Results: Seven reviews including 42 trials reporting on 57 outcomes were included. The most common nudge strategy was priming (69\%), then norms and messenger (40\%). Of the 57 outcomes, $86 \%$ had an effect on clinician behaviour in the hypothesised direction, and 53\% of those were statistically significant. For continuous outcomes, the median effect size was 0.39 (0.22, 0.45), while for dichotomous outcomes the median Odds Ratio was 1.62 (1.13, 2.76).

Conclusions: This review of 42 RCTs included in Cochrane systematic reviews found that the impact of nudge strategies on clinician behaviour was at least comparable to other interventions targeting implementation of evidence-based guidelines. While uncertainty remains, the review provides justification for ongoing investigation of the evaluation and application of nudge interventions to support provider behaviour change.

Trial registration: This review was not prospectively registered.

Keywords: Implementation intervention, Nudge, Healthcare provider, Guidelines, Review

\section{Contributions to the literature}

- This review describes the application and potential impact of nudge strategies on clinician implementation behaviour for trials included in Cochrane systematic reviews, and seeks to add to the field by highlighting strategies that may be typically overlooked in design of implementation interventions.

- This review suggests that nudge strategies, even when not part of a multicomponent intervention, could be useful in improving clinician behaviour.

- There is a need to better describe and classify nudge strategy in order to fully understand its impact on implementation in the healthcare setting.

\section{Introduction}

Evidence-based guidelines are developed specifically to improve the effectiveness of healthcare providers professional practice, reduce the risk of unintended adverse effects to the community and are fundamental tools for the translation of research into practice [1]. Research studies, however, consistently document poor implementation of evidence-based clinical guidelines [2]. Consequently, a large volume of research examining 'how' to best support healthcare providers to implement evidence-based clinical guidelines now exists. The Cochrane Effective Practice and Organisation of Care (EPOC) group have published over 100 systematic reviews which describe interventions designed to improve professional practice and the delivery of effective health services by implementing evidence-based clinical guidelines and practices [3]. A systematic review of reviews in primary care alone found 91 reviews which evaluated strategies such as audit and feedback, educational meetings and other practitioner targeted interventions, to improve clinical guideline adherence [4]. The intervention approaches and interpretations synthesised within these reviews have largely assumed that practitioners behave in a rational manner. As such, these interventions have actively targeted rational constructs such as attitudes, intentions and self-efficacy in an attempt to change behaviour.

However, recent behavioural research suggests that in many instances, an individual's behaviour and decisionmaking is not always perfectly rational [5]. Dual process models propose that individual decision-making and behaviour results from the interaction between two cognitive processes operating in parallel, one reflective, and the other impulsive or automatic [6]. In the provision of diabetes care, for example, studies have reported that 'automatic' decision-making processes operate alongside, and may mediate rational processes in influencing clinician provision of evidence-based care [7]. Additionally, a recent meta-analysis of nine studies assessing the association between 'habit' (which is an indicator of the automatic decision-making process) and clinician behaviour reported a moderate correlation $(r=0.33)[5,8]$. Such research suggests that interventions to change clinician behaviour need to move beyond strategies that focus purely on rational cognitive pathways, towards considering the context within which individual's act, which are influenced by automatic pathways.

Nudge strategies have been suggested as one way to influence habitual or automatic behaviour, by targeting the subconscious routines and biases that are present in human decision-making and behaviour [9]. 'Nudging' was first coined in 2008 and is defined as a 'function of any attempt at influencing people's judgement, choice or behaviour in a predictable way, that is made possible because of cognitive boundaries, biases, routines and habits in individual and social decision-making' (p158) [9]. These boundaries, biases and routines act as barriers for people to perform rationally consistent with their internal values. As such, nudge strategies work by 
targeting these boundaries, biases and habits by altering the underlying 'choice architecture', the social and physical environment in which the decision is made [9]. Specifically, 'choice architecture' involves the design of different ways in which choices can be presented to individuals. This can include influencing the range of choices (e.g. increasing number, types of choices), considering the manner in which the attributes are described (e.g. labelling, priming) and altering the way in which an object is presented (e.g. as a default, placement, presentation, sizing) [10]. This enhances the capacity for subconscious behaviours that aligns with the intrinsic values of an individual, without actively restricting options [11].

Nudge strategies are considered highly appealing from a policy and public health perspective as they are low cost and typically do not require ongoing resources to sustain. These interventions have been applied in public health policy to change behaviour and support healthier lifestyle choices. For example, many governments have applied nudges in the form of altered defaults, switching from opt in to opt out systems to increase organ donation rates. The United Kingdom (UK) Institute for Government and Behavioral Insights Team developed the Mindspace framework as a way to support the application of nudge strategies in public policy [12]. This framework describes the nine types of interventions (Mindspace: Messenger, Incentives, Norms, Defaults, Salience, Priming, Affect, Commitments, Ego) that are considered to have the most robust effects on the automatic system. Mindspace is underpinned by core principals of behavioural economics and aligns closely with other seminal lists describing nudge and choice architecture techniques [12, 13]. As such, this framework provides a structured way to support administrators, policy makers and researchers with selecting and applying nudge interventions to influence behaviour [12].

The potential impact of nudge strategies on clinician implementation behaviour has only recently started to be formally evaluated. A randomised controlled trial by Meeker found that a simple intervention encouraging practitioners to display a public poster stating their commitment to reduce inaccurate antibiotic prescription in waiting rooms, significantly reduced inappropriate prescribing rates relative to the control group (- 19.7\% [95\% confidence interval: $-5.8 \%$ to -33.4 ] $; p=0.02$ ) [14]. The UK Behavioural Insights team undertook a randomised $2 \times 2$ factorial trial examining the impact of providing social norm feedback to high antibioticprescribing GPs within their team. The study found that providing information concerning providers' prescribing rate, compared with other local practices (norm) in the area from England's chief medical officers (messenger), significantly reduced the rate of antibiotic items dispensed per 1000 population $(p<0.0001)$ [15].

Given the potential of 'nudge' strategies to impact on clinicians' behaviours, efforts to describe the application and potential effect of such strategies on implementation are warranted. An overview of the type of settings and behaviours that have been targeted can highlight opportunities for future empirical research, and inform the design of low-cost implementation strategies.

This review aims to describe the application and effects of nudge strategies on healthcare provider and organisations' implementation of evidence-based guidelines, policies and practices. The review will use data from randomised controlled trials included within Cochrane systematic reviews

\section{Methods}

This review has been reported in accordance to the PRISMA guidelines [16]. This review was not registered, and a protocol has not been previously published.

\section{Information sources and search strategy}

The nudge terminology was developed in 2008 and has gained popularity in the last decade. Implementation trials testing the impact of nudge strategies, however, may have been performed over many decades. Many interventions that would have been classified as nudge are not published under this term. Given this, conventional electronic searches of bibliographical databases are unlikely to be sufficiently sensitive or specific, and are likely to result in conflated numbers and potentially missed studies. To avoid this, we conducted a targeted and systematic search of studies included within eligible Cochrane systematic reviews. The Cochrane library was chosen as it is internationally recognised for publishing up to date, high-quality and current systematic reviews in healthcare settings, and has a review group dedicated to publication of studies to improve healthcare professional practices [17]. We undertook a two-stage screening process, where systematic reviews were screened for eligibility and following that, trials within eligible reviews identified in the first process assessed for inclusion. Two authors (SLY, FS) screened the titles, abstract and full text of all reviews published by the Cochrane library in the last 2 years (2016-2018) on December 2018. This timeframe was selected as Cochrane authors are encouraged to update their reviews every 2 years.

\section{Study selection}

Following this, full text of all included studies within eligible reviews were screened by at least two authors (SLY, FS, RS). Studies were included if they met all eligibility criteria described below. All disagreements were resolved via a consensus process between the two 
reviewers and involved a third reviewer (LW) where necessary.

\section{Eligibility criteria}

All studies that examined the impact of a nudge strategy targeting clinician and healthcare organisation's implementation of health-related guidelines, policies and practices were included if they met the following criteria.

\section{Types of studies}

Only randomised controlled trials (RCTs) with a parallel control group that compared (i) an intervention that included a nudge strategy to improve the implementation of a healthcare-related guideline, policy and practice in healthcare settings/organisations compared with a nonnudge intervention or usual practice; and (ii) two or more different strategies, which included at least one arm with a nudge strategy, to improve the implementation of a healthcare-related guideline, policy and practice were included. Studies also had to specify the implementation of a health-related policy, guideline and practice as an explicit aim of the study, and as such were likely to be type 2 or type 3 hybrid trials [18].

\section{Type of participants}

Study participants were clinicians (medical doctors, allied health professionals) providing care in healthcare/ clinical settings. Healthcare settings included acute care hospitals; long-term care facilities, such as nursing homes and skilled nursing facilities; physicians' offices (i.e. primary care); urgent-care centres; outpatient clinics; home healthcare (i.e. care provided at home by professional healthcare providers) and emergency medical services [19].

\section{Type of intervention}

The intervention had to include at least one nudge strategy. The determination of whether a nudge strategy was present was undertaken by at least three reviewers (SY, FS, AA) for each study. Nudge strategies were defined as those that 'applied principles from behavioural economics and psychology to alter behaviour in a predictable way without restricting options or significantly changing economic incentives' (p6) [11]. These strategies were those that targeted the automatic decision-making processes rather than the rational decision-making processes [20]. Strategies were classified using the Mindspace framework (see Table 1) [20]. The Mindspace framework was chosen as it provides a practical checklist for summarising the application of nudge strategies in public health practice. Similar to a previous review [21], strategies were classed as (i) priming, (ii) norms and messenger, (iii) salience and affect, (iv) default, (v) commitment and ego and (vi) incentives [22]. For studies with multiple intervention arms (e.g. multiarm RCTs, factorial trials or comparative effectiveness trials), only the arm/s that included an intervention with a nudge strategy were included. Multiple intervention arms with nudge strategies were combined as in most instances the intervention arms included the same type of nudge strategy. Where the intervention was multicomponent and included both nudge and non-nudge strategies, this was also included. Trials that included a nudge strategy in the control arm were excluded to allow the impact of the nudge strategies to be assessed relative to no nudge strategy.

\section{Type of outcomes}

We included any subjective or objective measure of implementation outcomes. Similar to previous reviews carried out by the team $[23,24]$, implementation outcomes were those that described the fidelity or execution of a guideline, policy or practice at an organisational or practitioner level. Such outcomes could be assessed via selfreported surveys, observations or from other routine data sources including electronic medical records.

Table 1 Nudge categories and description applied in the review based on the Mindspace framework

\begin{tabular}{|c|c|}
\hline $\begin{array}{l}\text { Categories of nudges using the } \\
\text { Mindspace framework }\end{array}$ & Description \\
\hline Priming & $\begin{array}{l}\text { Subconscious cues which might be physical, verbal or sensational and are changed to nudge a } \\
\text { particular choice }\end{array}$ \\
\hline Salience/affect & $\begin{array}{l}\text { Novel, personally relevant vivid examples and explanations that are used to increase attention to a } \\
\text { particular choice }\end{array}$ \\
\hline Default & A particular choice is 'preset', making it the easiest option \\
\hline Incentive & $\begin{array}{l}\text { Incentives to reinforce a positive choice, or penalties to discourage a negative choice. Such incentive } \\
\text { however should not be enough to result in economic gains }\end{array}$ \\
\hline Commitment/ ego & $\begin{array}{l}\text { Making a commitment/ ego or public promise in order to elevate one's desire to feel good about } \\
\text { themselves }\end{array}$ \\
\hline Norms and messenger & $\begin{array}{l}\text { Using the practices of peers or others to establish a norm. People of status, professional organisations } \\
\text { and peer leaders used to communicate with individuals }\end{array}$ \\
\hline
\end{tabular}


Examples of such outcomes include appropriate prescribing or test ordering in line with guideline recommendations.

Studies were excluded if they were not published in English. There were no other exclusions beyond that specified by the original review the studies were extracted from.

\section{Data extraction}

Relevant information was extracted from the published Cochrane reviews, the primary trial and other associated papers referenced in the primary trial by at least two individuals (FS, RS, JJ, BM) using a standardised data extraction form. This included (1) study informationauthor name, study design, country, date of publication, type of healthcare provider/organisation, participant/service demographic/socioeconomic characteristics and number of experimental conditions; (2) characteristics of the overall implementation strategy, including the duration, number of contacts and approaches to implementation, and information to allow classification of the intervention strategy into nudge categories according to Table 1 (priming, norms and messenger, salience and affect, commitment and ego, incentives and default nudge); (3) trial primary or summary outcome measures and results, including the data collection method, validity of measures used, effect size (or raw data that allowed the calculation of an effect size) and measures of outcome variability; and (4) risk of bias assessment as published in the Cochrane reviews [25]. Where several implementation outcomes were reported, we extracted only the results and risk of bias assessment for those explicitly described as the primary outcome(s) of the trial, for all follow-up time periods. Where the primary outcome was not specified in the individual trial, we extracted the variable(s) described in the sample size calculation.

\section{Data analysis}

To describe the application of nudge strategies in practice, we calculated the number and percentage of trials using each nudge strategy, according to the Mindspace framework. We also described the application of nudge strategies according to setting and type of outcomes assessed. Where the primary outcomes were clearly identified in the aims or via sample size calculation, we calculated the within-study effect for this outcome. Where there were several primary outcomes, we focused on all implementation outcomes and calculated a pooled effect size for that study, if the outcomes were similar. Where they were different, we calculated the withinstudy effect for each outcome separately. We also calculated the within-study effects for outcomes reported at multiple time-points for each time-point.
Due to substantial clinical and methodological heterogeneity of included trials, it was not appropriate to conduct a meta-analysis. Instead, we summarised the effect estimates and used vote-counting methods, as outlined in the Cochrane Handbook, for where a meta-analyses was not possible [26]. We calculated within-study point estimates and 95\% confidence intervals (CIs). For all studies, we extracted the raw values (mean, standard deviation, median interquartile range (IQR) and range for continuous outcomes; and percentages and frequencies for dichotomous outcomes). We used this data in the estimation of within-study effects. For continuous outcomes, we calculated the effect size as the difference in follow-up scores between intervention and control, except for one study that only reported the change in outcomes for control and intervention. The difference in change scores was used for this study [27]. For dichotomous outcomes, we calculated odds ratio (OR) as the measure of intervention effect. Odds ratios were chosen as it is a relative measure that is less sensitive to differences in baseline values than absolute measures such as risk differences. Additionally, ORs are also not as influenced by the underlying prevalence of the outcome as other relative measures [28]. We calculated within-study effects for all outcomes together with 95\% CIs. The direction of a favourable intervention effect varied across studies, with some studies aiming for a reduction, and others aiming for an increase in a behaviour. Where studies aimed for a reduction, we reverse-scored these values. To provide an overview of overall impact, and by nudge strategy, we reported the number of studies and outcomes with an estimated effect in the beneficial direction as well as the percentage of effects favouring the intervention. These results were summarised in harvest plots, which visually demonstrate the directional effects of an intervention strategy and are recommended to help summarise review results when meta-analysis is not appropriate [29]. Finally, we calculated the median standardised mean effect size for continuous outcomes and median OR for dichotomous outcomes and IQR.

Statistical analyses were programmed using SAS v9.4 [30], Stata v13.0 and R [31, 32].

\section{Clustered studies}

All clustered trials were examined for unit of analysis errors to calculate within-study effects. For cluster randomised trials, the effective sample size was calculated and used for all estimates of effect sizes. This was undertaken to allow for inclusion in the harvest plots so that the potential impact of nudge strategies can be considered in light of the size of the studies. To calculate the effective sample size, the intracluster correlation coefficient (ICC) derived from the trial (if available) or from another source (for example, the ICC used in the 
sample size calculation, or the mean ICC calculated from the other included studies) was used, and the design effect calculated using the formula provided in the Cochrane Handbook for Systematic Reviews of Interventions [33].

\section{Studies with more than two treatment groups}

Procedures described in the Cochrane Handbook for Systematic Reviews of Interventions [33] were followed for trials with more than two intervention or comparison arms that included a nudge strategy. This involved combining multiple intervention arms following the recommended formula set out by the Cochrane Handbook. Only intervention arms that included relevant nudge strategies as part of the intervention package were combined and compared to the control group. Multiple comparison arms were combined, rather than described separately, to help focus this review.

\section{Results}

\section{Review characteristics}

A total of 1730 systematic reviews published in the last 2 years (2016-May 2018) were obtained from the
Cochrane library database. Forty-three full-text reviews were included in the full text screen and of those, 36 reviews were excluded for the following reasons: did not examine implementation outcomes $(n=33)$ [34-66], not undertaken in healthcare settings $(n=1)$ [67], not quantitative $(n=1)$ [68], or was a review of previous systematic reviews $(n=1)$ [69].

A total of seven reviews that examined a range of health-related practices including antibiotic prescribing [70], hand hygiene [71], management of obesity [72], management of musculoskeletal conditions [73], uptake of clinical guidelines across health behaviours [74, 75], and provision of mental healthcare [76] were included.

From these seven included reviews, 55 eligible RCTs that met all the inclusion criteria were included. Of these, 13 studies were excluded from the analysis: six did not report sufficient detail for calculation of a withinstudy effect [77-82], six included a nudge strategy in the control group [83-88], and one reported using an inconsistent outcome (time to event) [89]. Thus, a total of 42 studies, reporting across 57 outcomes, were included in the final analyses. Figure 1 contains a PRISMA flowchart of the study selection process.

Nudge Strategies to Improve Implementation

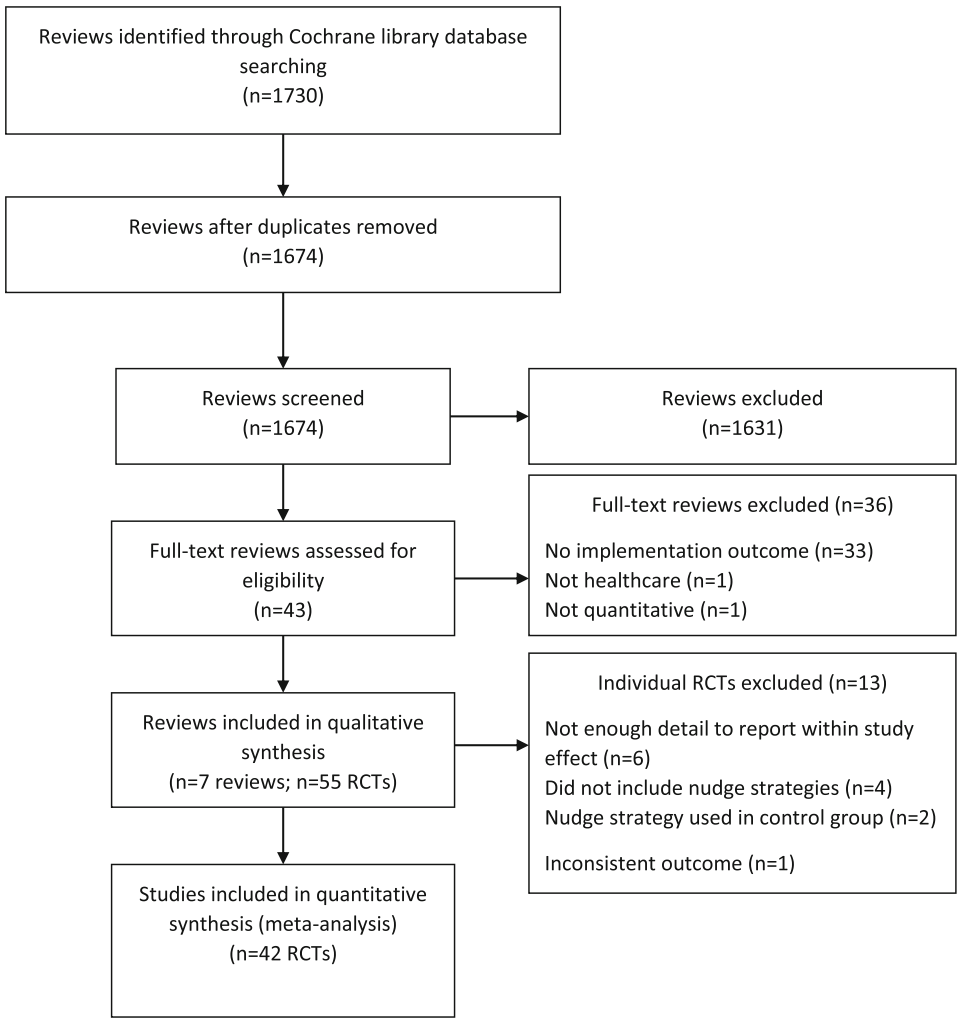

Fig. 1 PRISMA flowchart of study selection process 


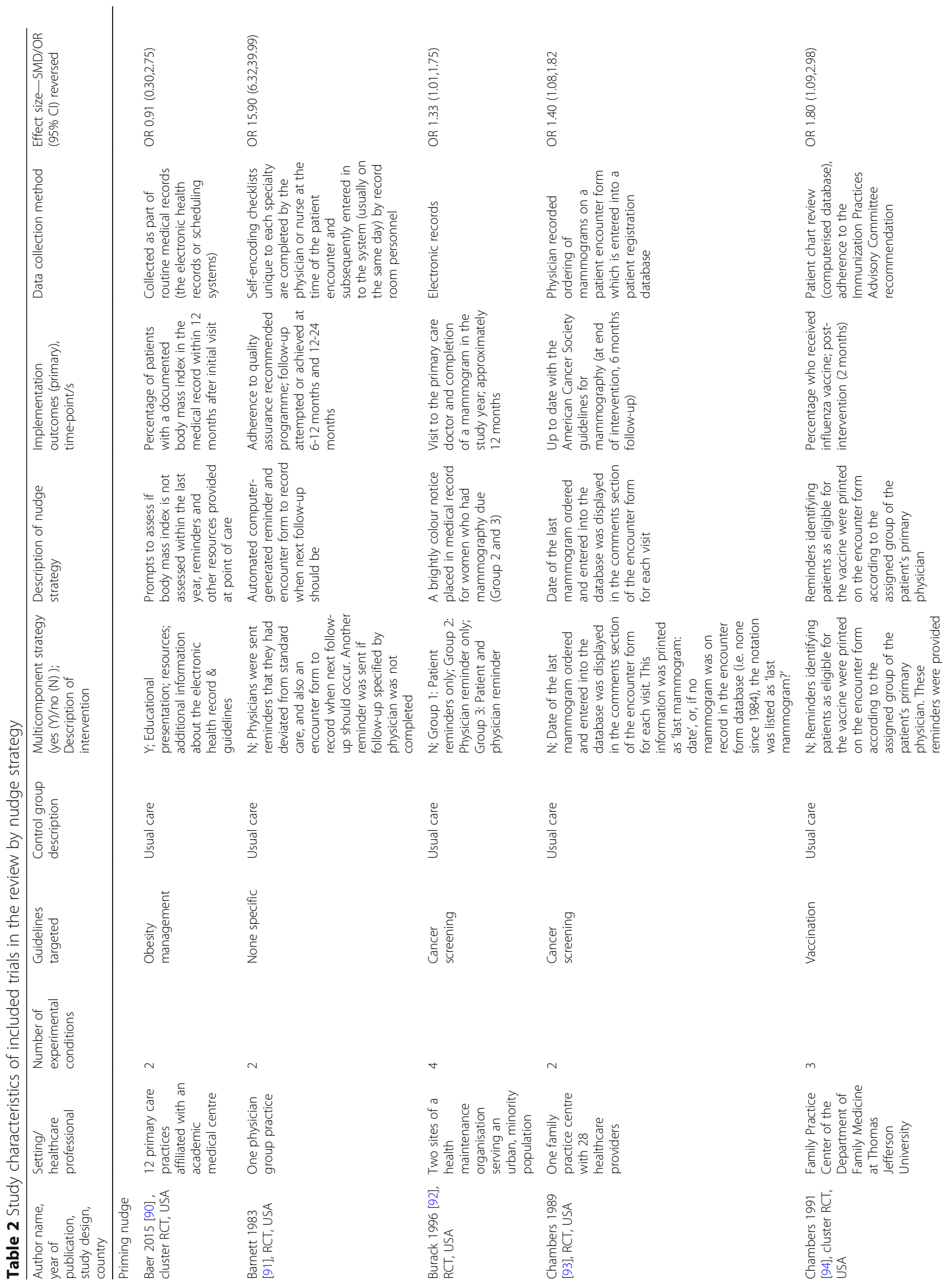




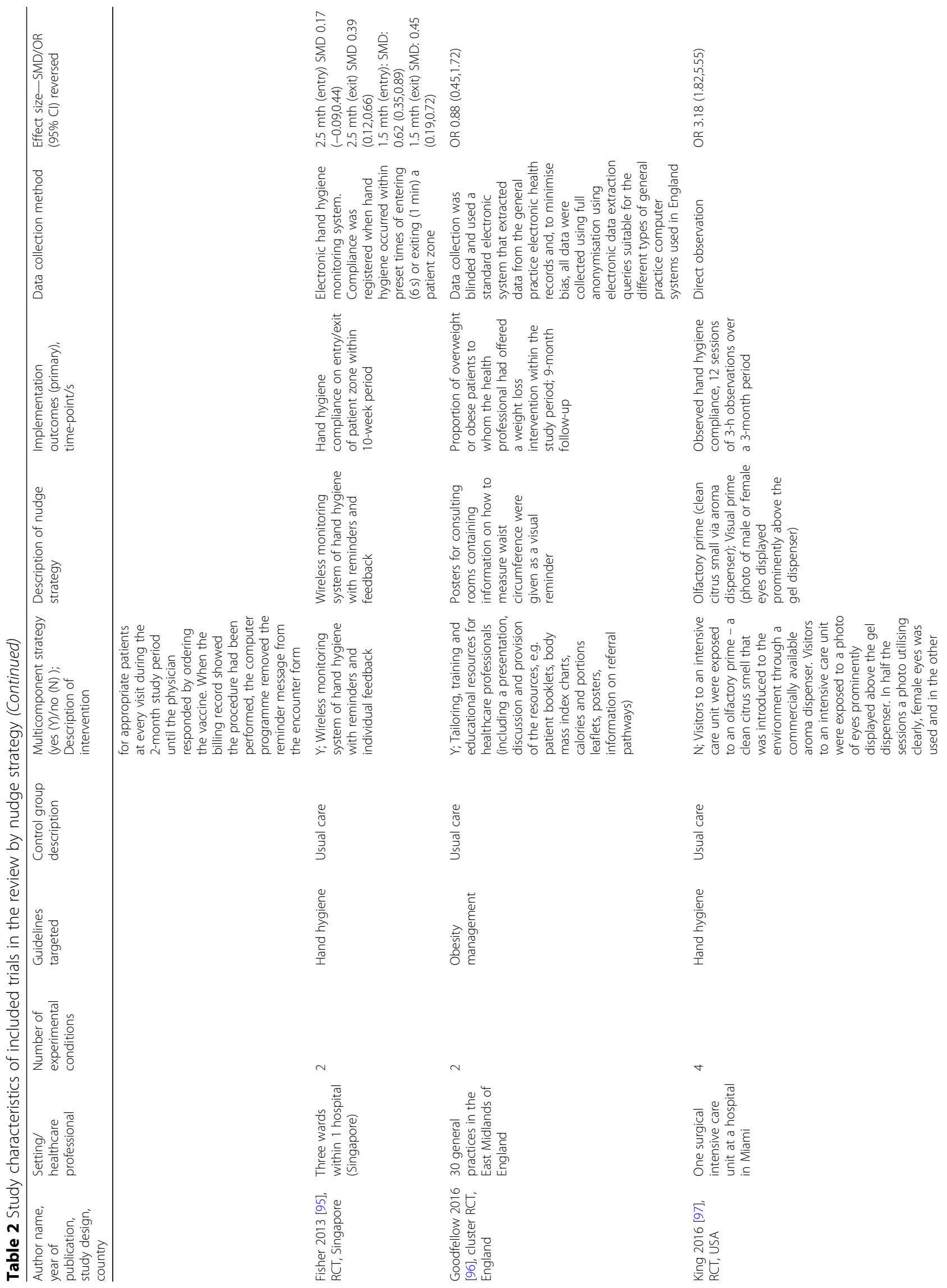




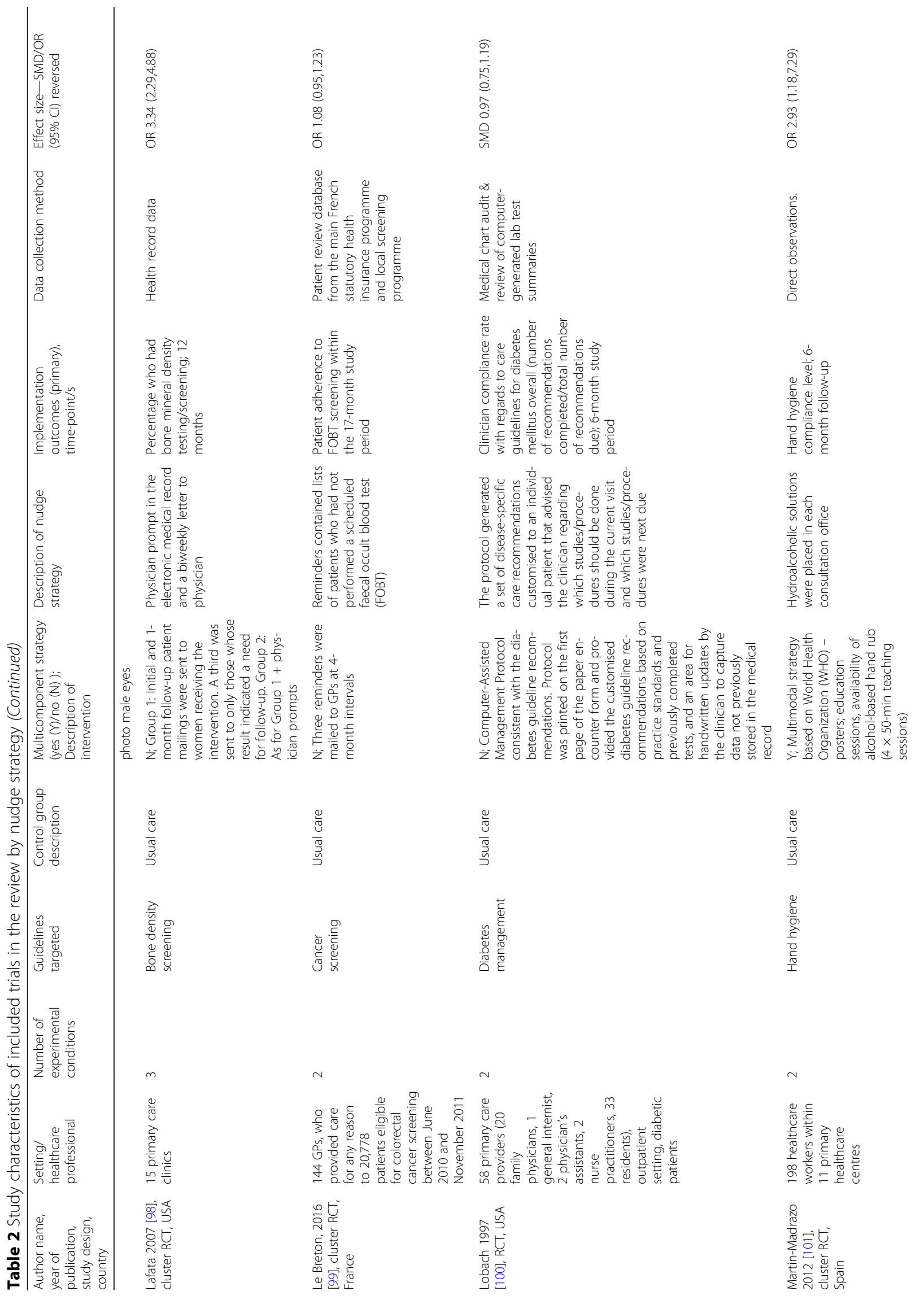




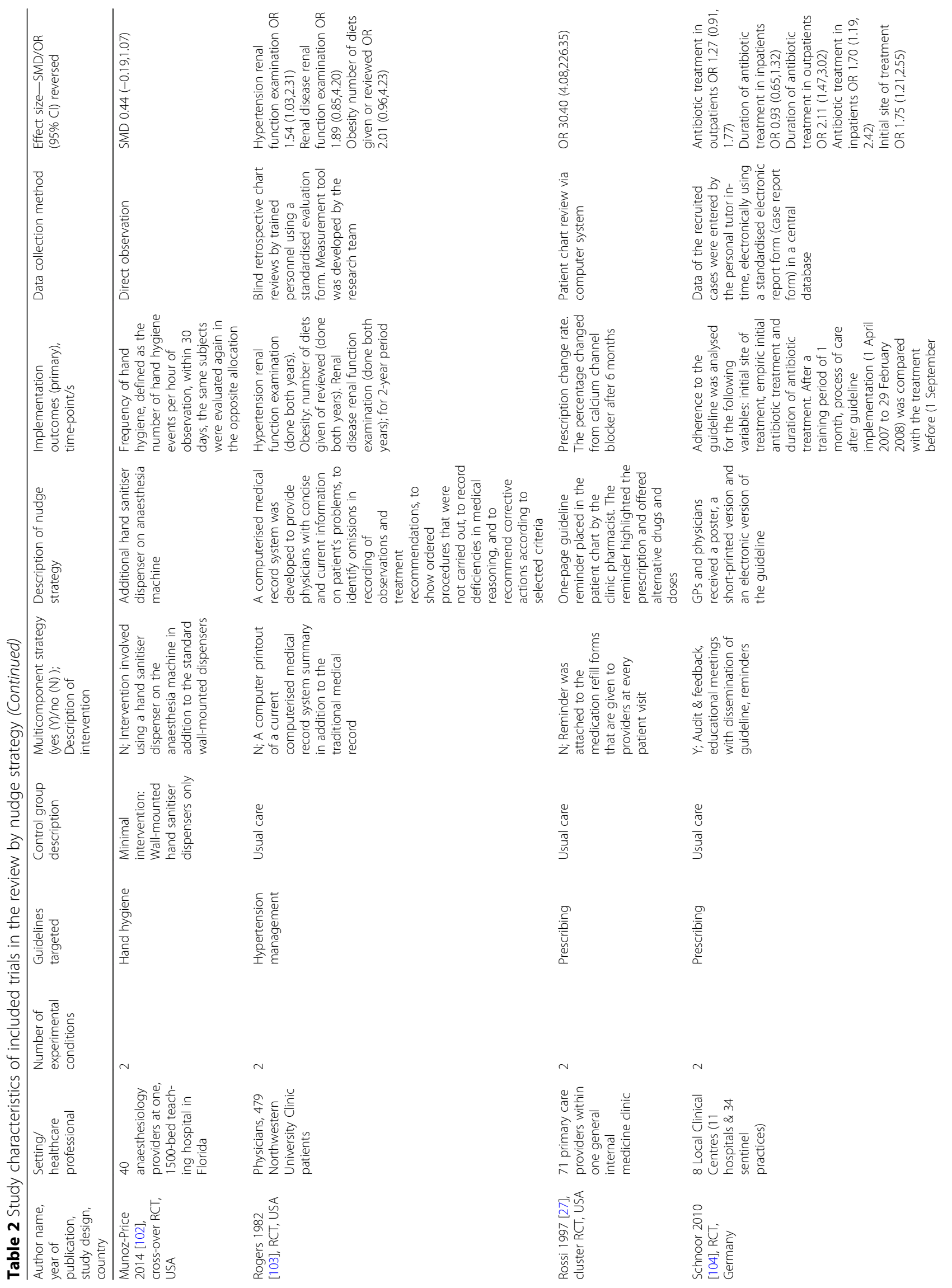




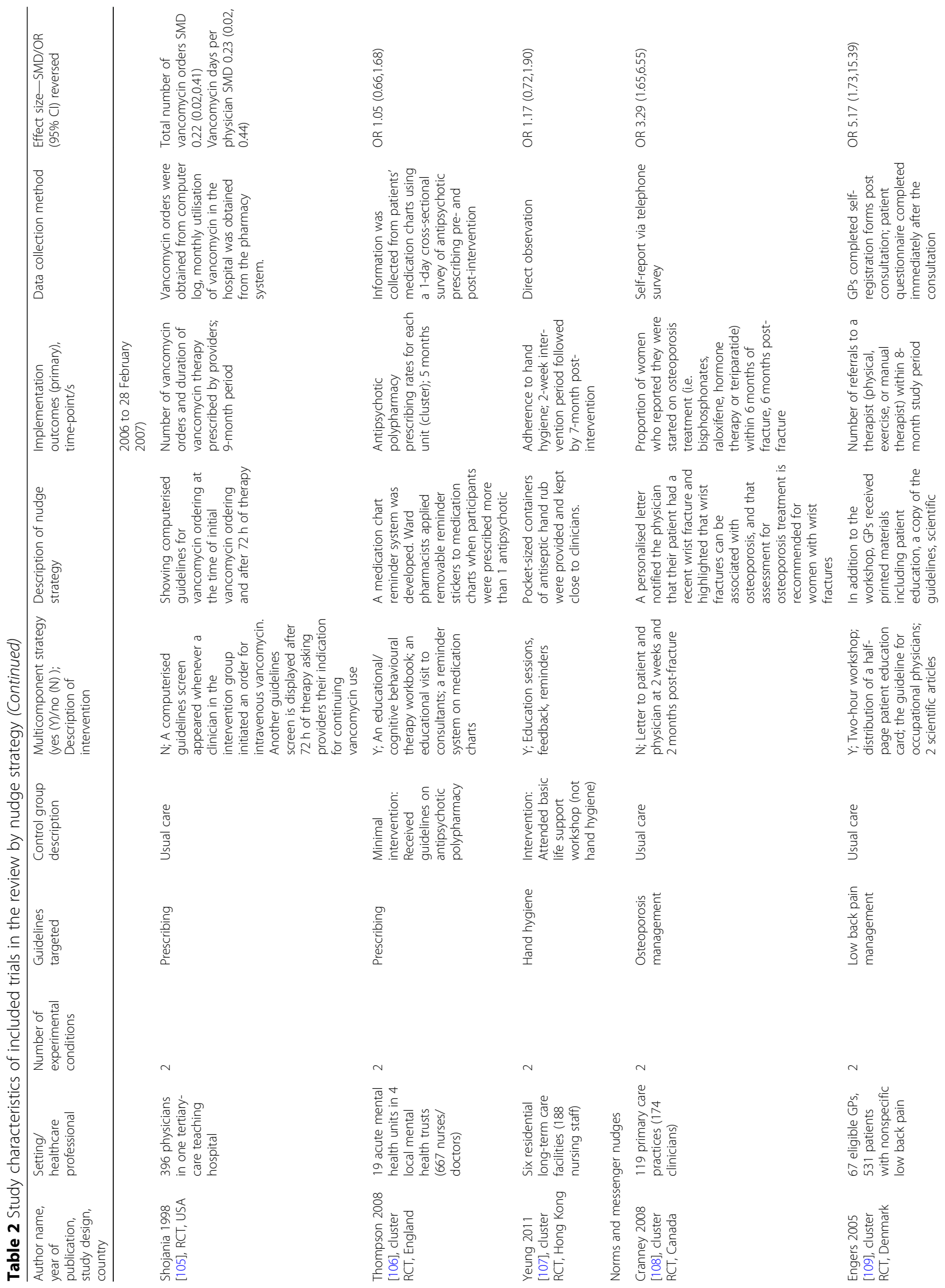




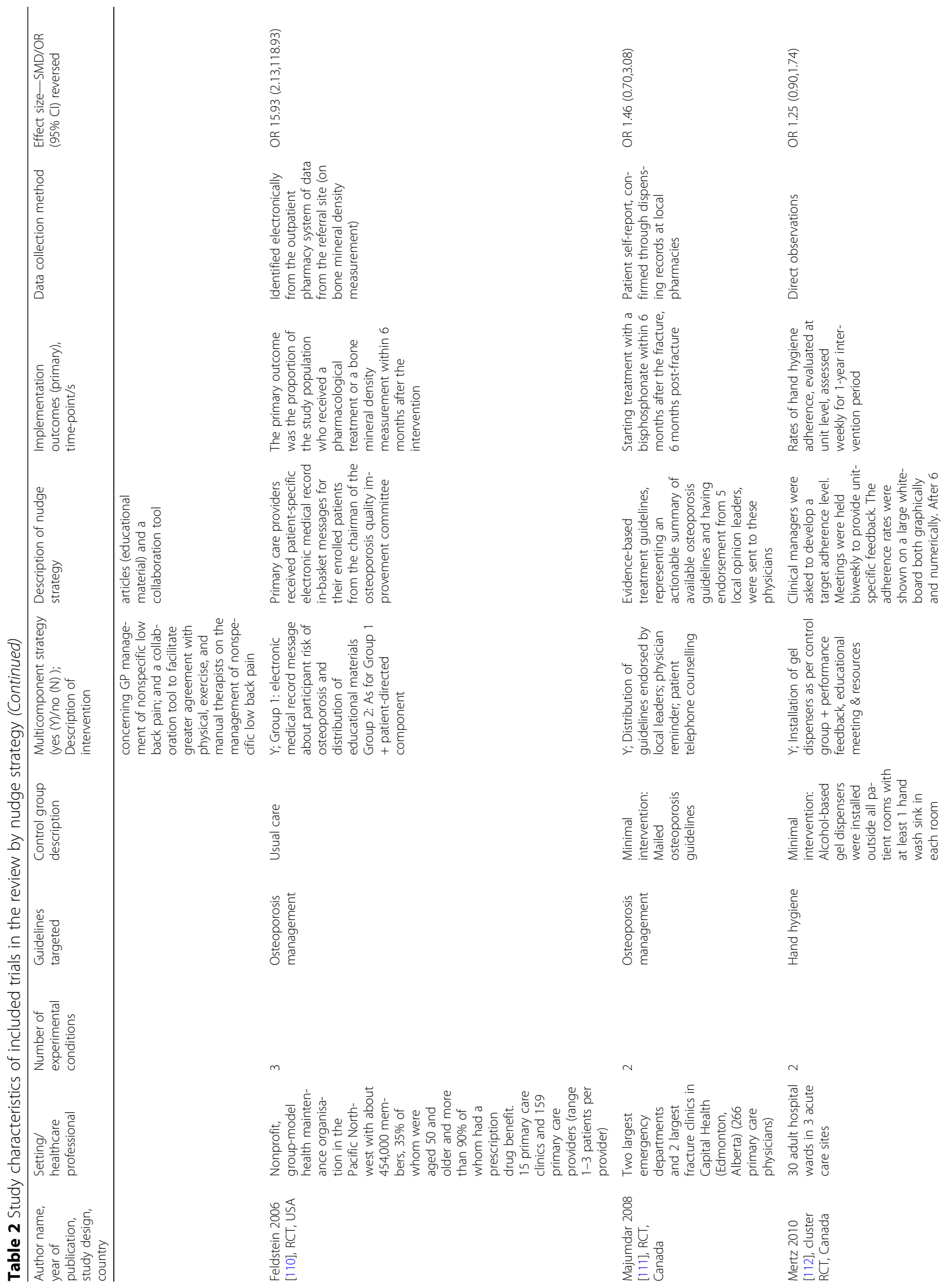




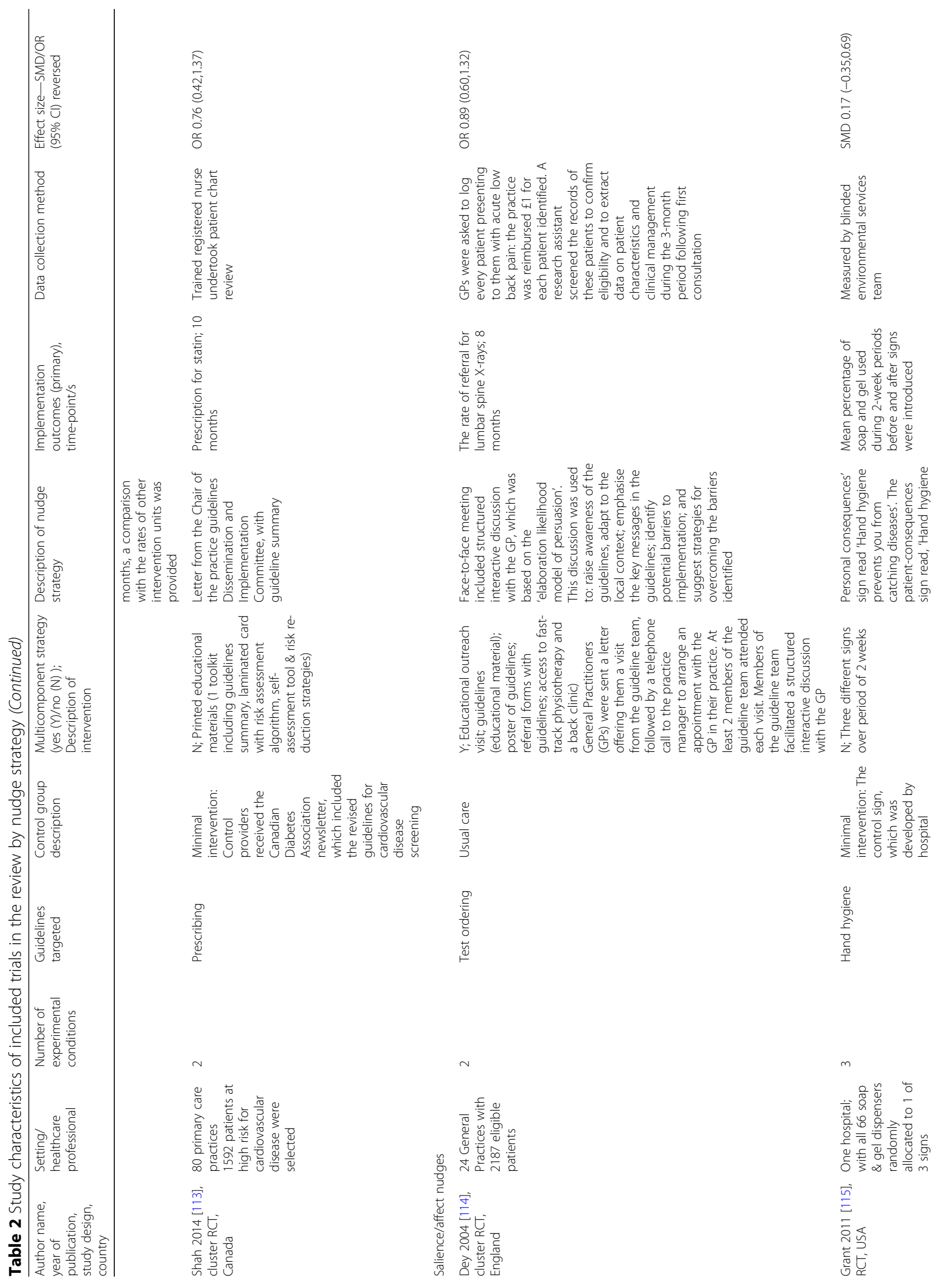




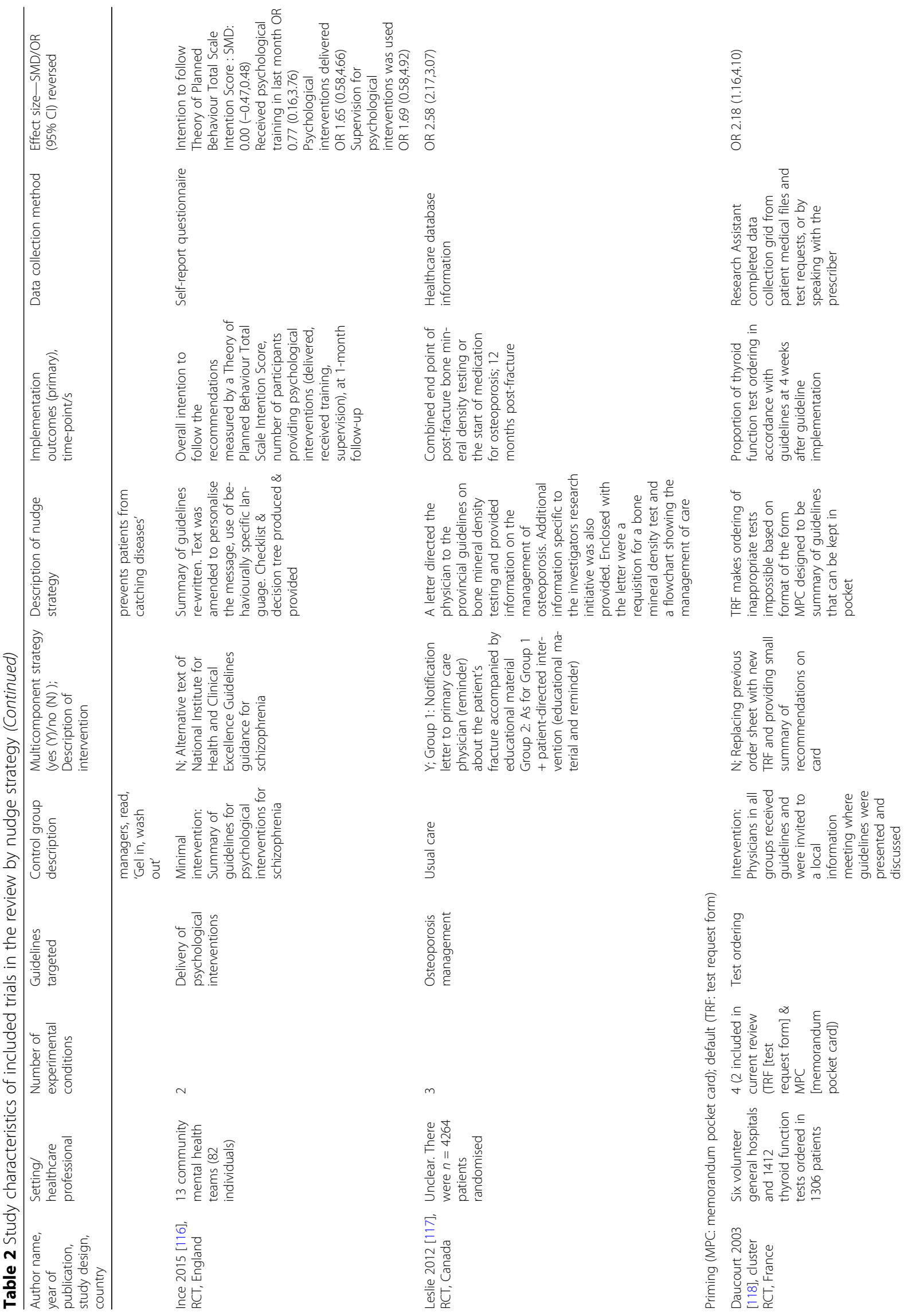




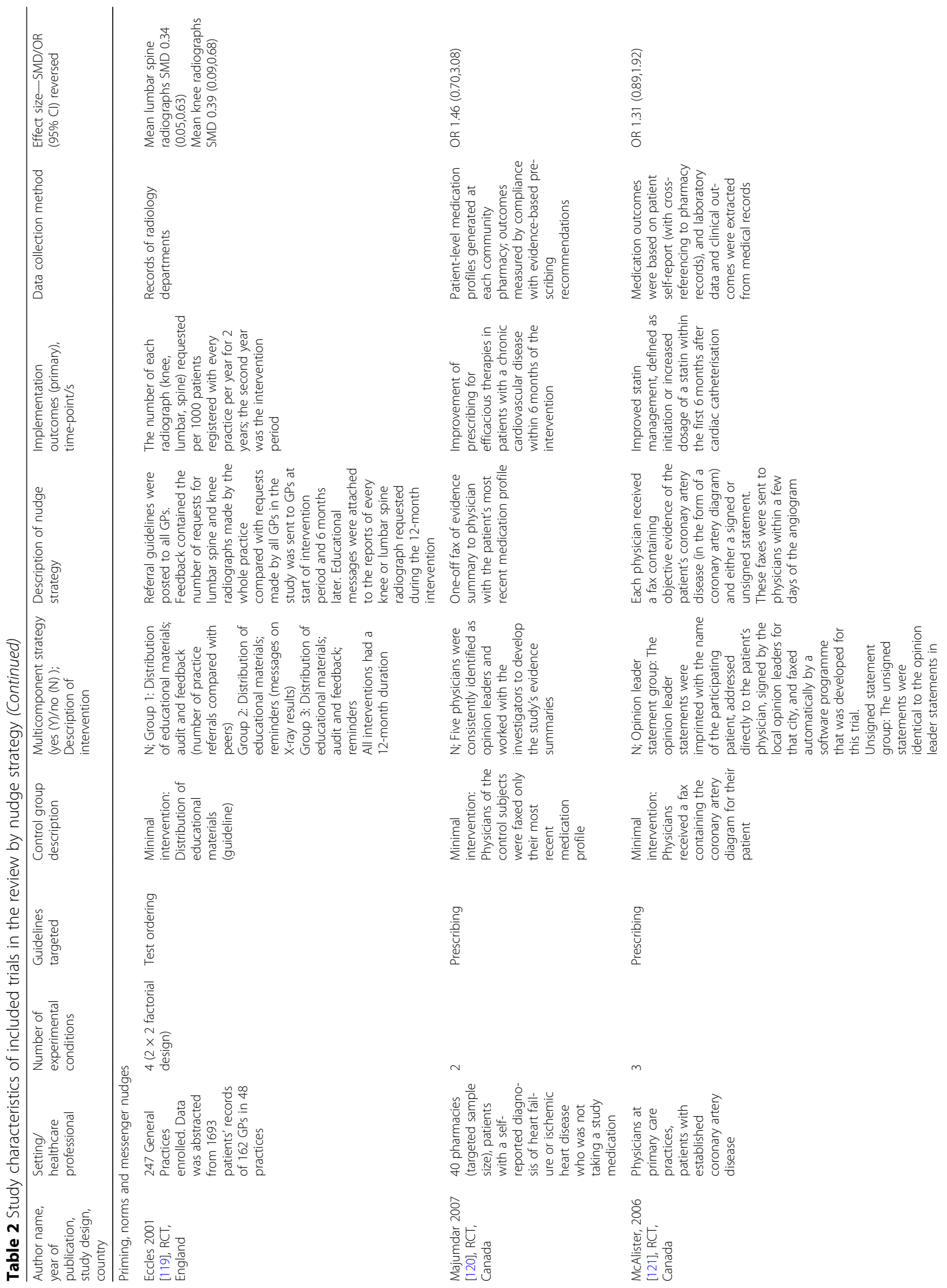




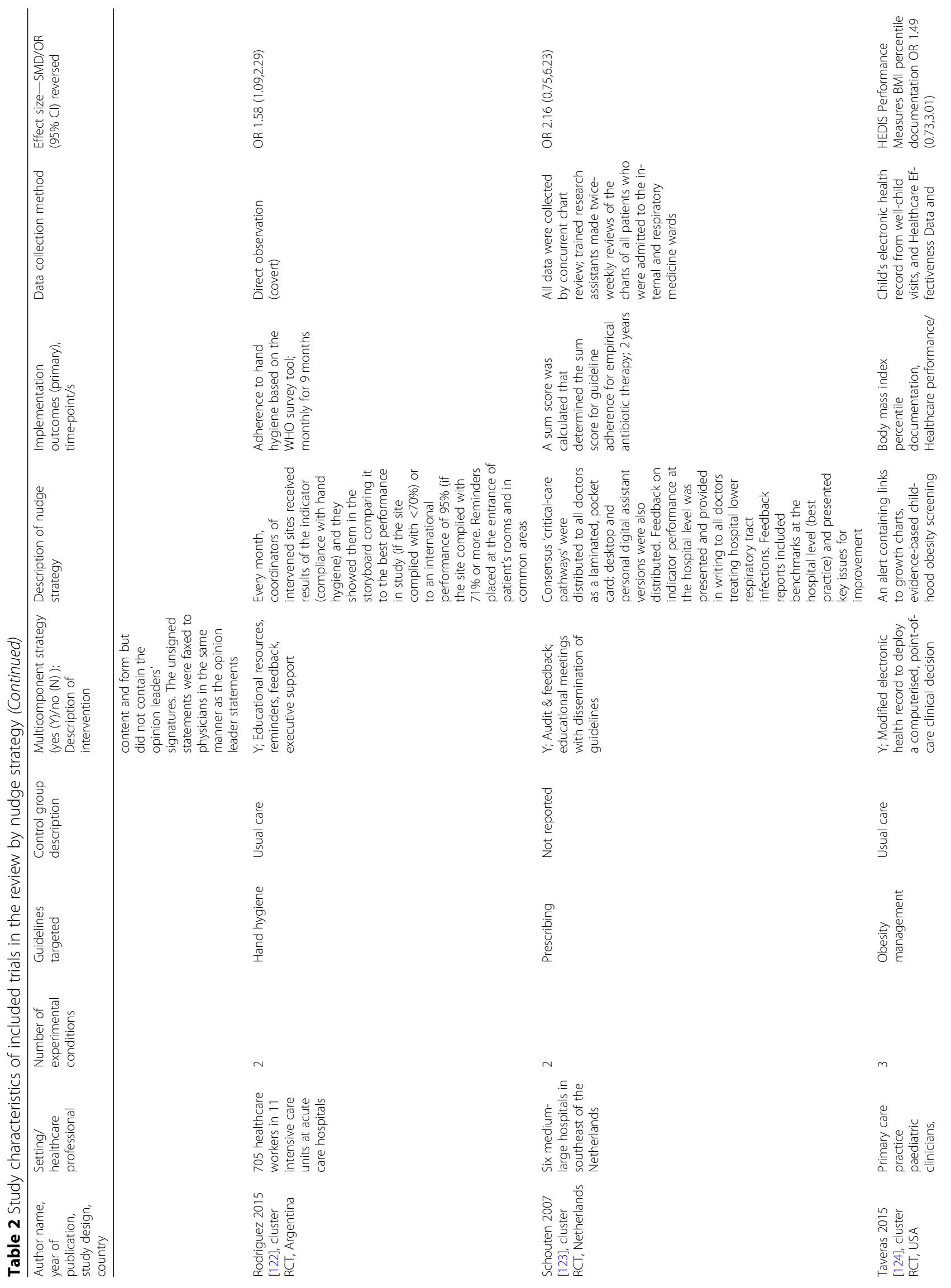




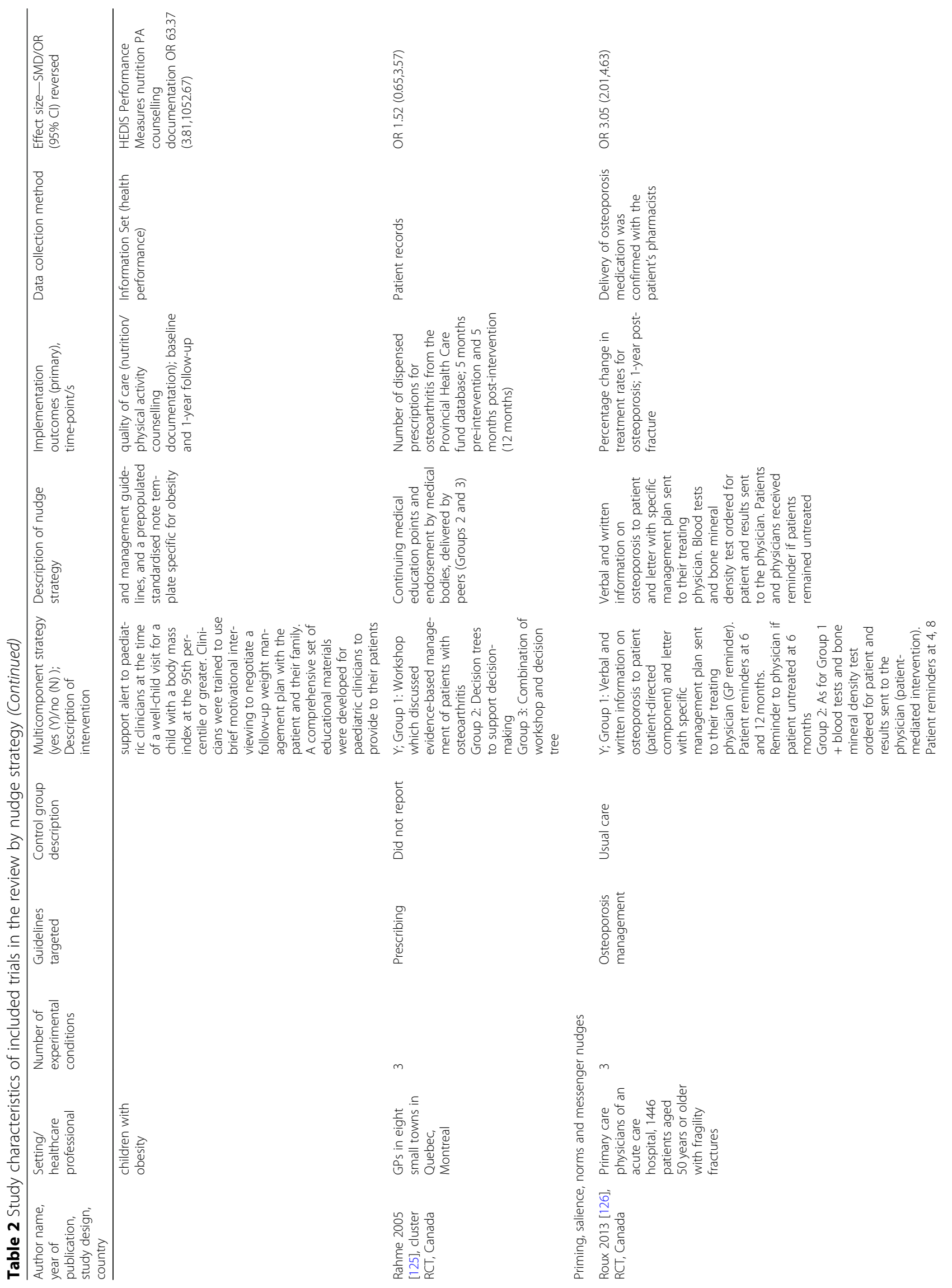


Young et al. Implementation Science

(2020) 15:50

Page 18 of 30

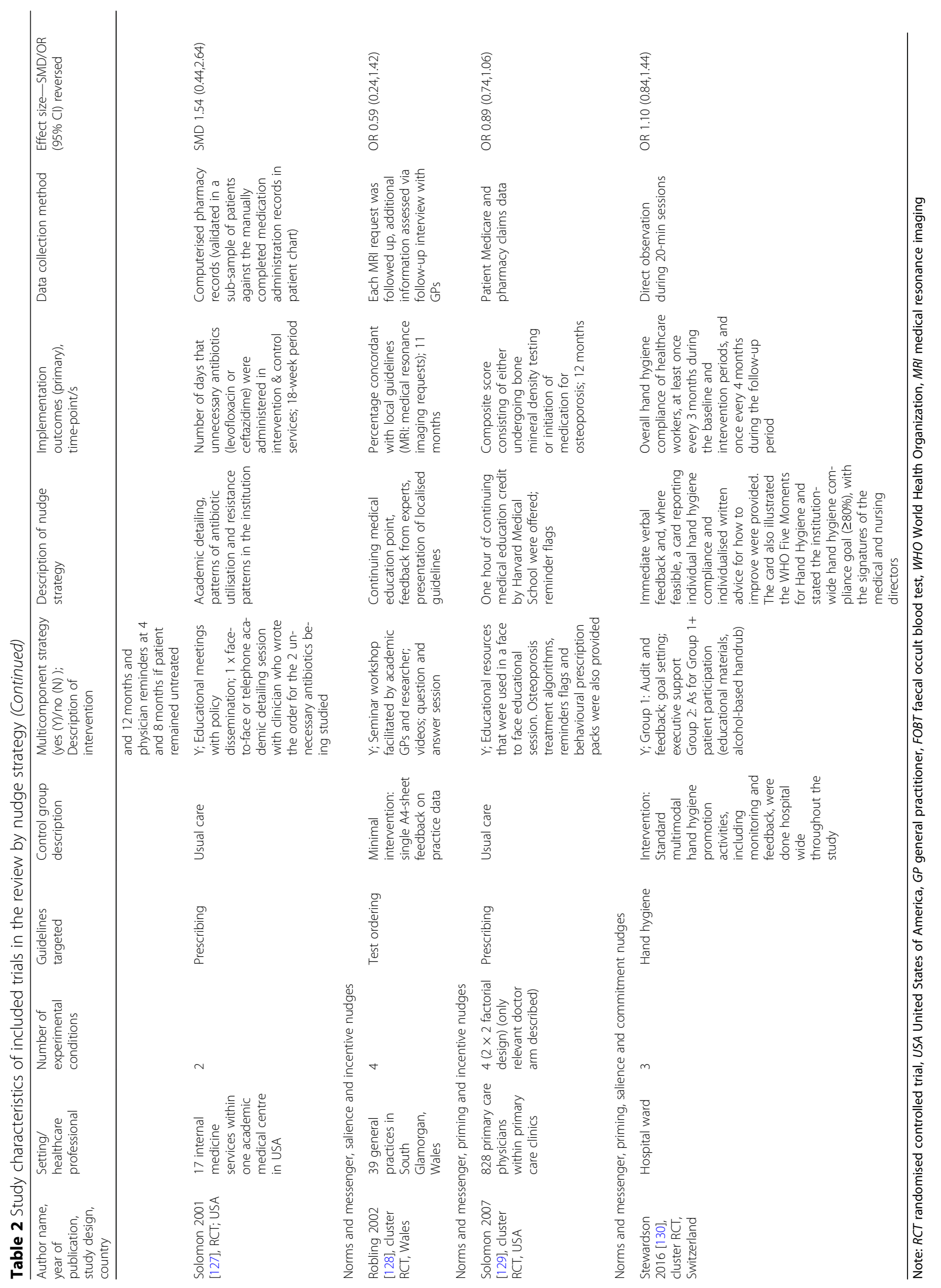




\section{Study characteristics}

Table 2 provides an overview of the included studies. Most studies were conducted in the USA $(40 \% ; n=17)$, Canada $(21 \% ; n=9)$ and the UK $(14 \% ; n=6)$. Over half included two experimental arms, including the control $(n=26 ; 62 \%), 24 \%$ included three arms $(n=10)$ and $14 \%(n=6)$ included four arms. Over half of the studies were cluster trials $(52 \%, n=22)$, one was a cross-over RCT [102] and the remainder were simple RCTs. Over half of the studies employed a control group that consisted of usual care or no intervention strategy $(62 \%, n=$ 26). Over a quarter used a minimal intervention $(26 \%, n$ $=11$ ) which included strategies such as provision of guidelines, written recommendations, and introduction of facilities or equipment, and $7 \%(n=3)$ used an intervention as part of the control, including education sessions to provide information; reminders and feedback targeting adequate products and facilities, provision of encouragement, monitoring and feedback and support. A further two studies [123, 125] did not provide sufficient detail of the control group.

\section{Methodological quality of included studies}

The risk of bias for each RCT as reported in the Cochrane reviews is presented in Table 3. Over half of the trials were judged as low risk for selection bias (random sequence generation $(n=33)$, allocation concealment $(n=28)$ and attrition bias (incomplete outcome data $(n=32))$. A large number of trials were judged as unclear for selective reporting $(n=20)$ and protection against contamination $(n=14)$. In terms of blinding of outcome assessment, 21 trials were judged as having a low risk of bias (see Table 3). Overall, 29 studies (69\%) met at least half of the criteria they were assessed against.

\section{Application of nudge strategies to improve implementation}

All nudge strategies were used in at least one trial to influence healthcare provider adherence to guideline recommendations. Twenty-two studies across 30 outcomes incorporated nudge strategies as part of a multicomponent intervention, while the remainder examined the impact of nudge strategies in isolation $(n=20)$. Ten studies applied two nudge strategies and three applied three or more nudge strategies. The frequency to which each strategy was used and specific examples of their application are shown in Table 4.

\section{Priming nudge}

The most commonly used nudge strategy was priming, which was included in 69\% $(n=29)$ of trials, across 41 outcomes. The impact of this nudge strategy was assessed on a range of implementation outcomes including adherence to antibiotic prescribing guidelines $[104,105,123]$, prescribing rates of medication and test ordering of various conditions [27, 92, 93, 98, 99, 103, $106,118,119,121,129,131]$, vaccinations [94], provision of care according to guidelines [90, 91, 96, 100, 103, 124, 126], and adherence to hand hygiene guidelines [95, 97, $101,102,107,122,130]$. Priming nudges were also applied in various clinical settings including hospitals [95, $102,104,118,122,130]$, primary care practices $[27,91$, 93, 94, 96, 99-101, 103, 119, 121, 124], mental health units [106] and community-based long-term care facilities [107].

\section{Norms and messenger nudge}

Norms and messenger nudge were the second most commonly used nudge strategy, included in $40 \%$ of studies $(n=17)$ across 19 outcomes. The impact of this strategy on a number of implementation outcomes including appropriate prescribing of medication $[108,111$, $113,125,127,132]$, and test ordering for various conditions [110, 119], antibiotic prescribing [123, 127], provision of preventive/lifestyle care according to guidelines $[109,124]$ and adherence to hand hygiene guidelines $[112,122,130]$ was assessed. Interventions were undertaken in various clinical settings including hospitals $[111,112,122,127,130]$, primary care practices [108-110, 113, 119, 121, 133] and pharmacies [131].

\section{Salience and affect nudge}

This was the third most frequently used nudge strategy, utilised in 19\% of the studies reviewed $(n=8)$, across 11 outcomes. This was undertaken in interventions in hospitals $[115,127]$, primary care practices $[114,126]$ and community mental health teams [116] to improve test ordering (i.e. screening for bone mineral density) [114, $117]$, hand hygiene $[115,130]$, provision of care according to various guidelines (i.e. mental health) $[116,126$, 128] and antibiotic prescribing [127].

\section{Incentive, commitment/ego and default nudge}

Less than $10 \%$ of studies incorporated either incentive ( $n$ $=3)$, commitment/ego $(n=1)$ or default $(n=1)$ nudge strategies as part of their interventions. The one study that used a commitment/ego nudge was conducted in hospitals to increase adherence to hand hygiene where clinicians publicly declared their commitment to either reduce inappropriate behaviour or increase recommended behaviour [130]. A default nudge was used in one study conducted in hospitals where test ordering options related to thyroid function not relevant to patients were shaded out based on ordering forms and incentive strategies [118]. The incentive strategy primarily included provision of certificates and professional 


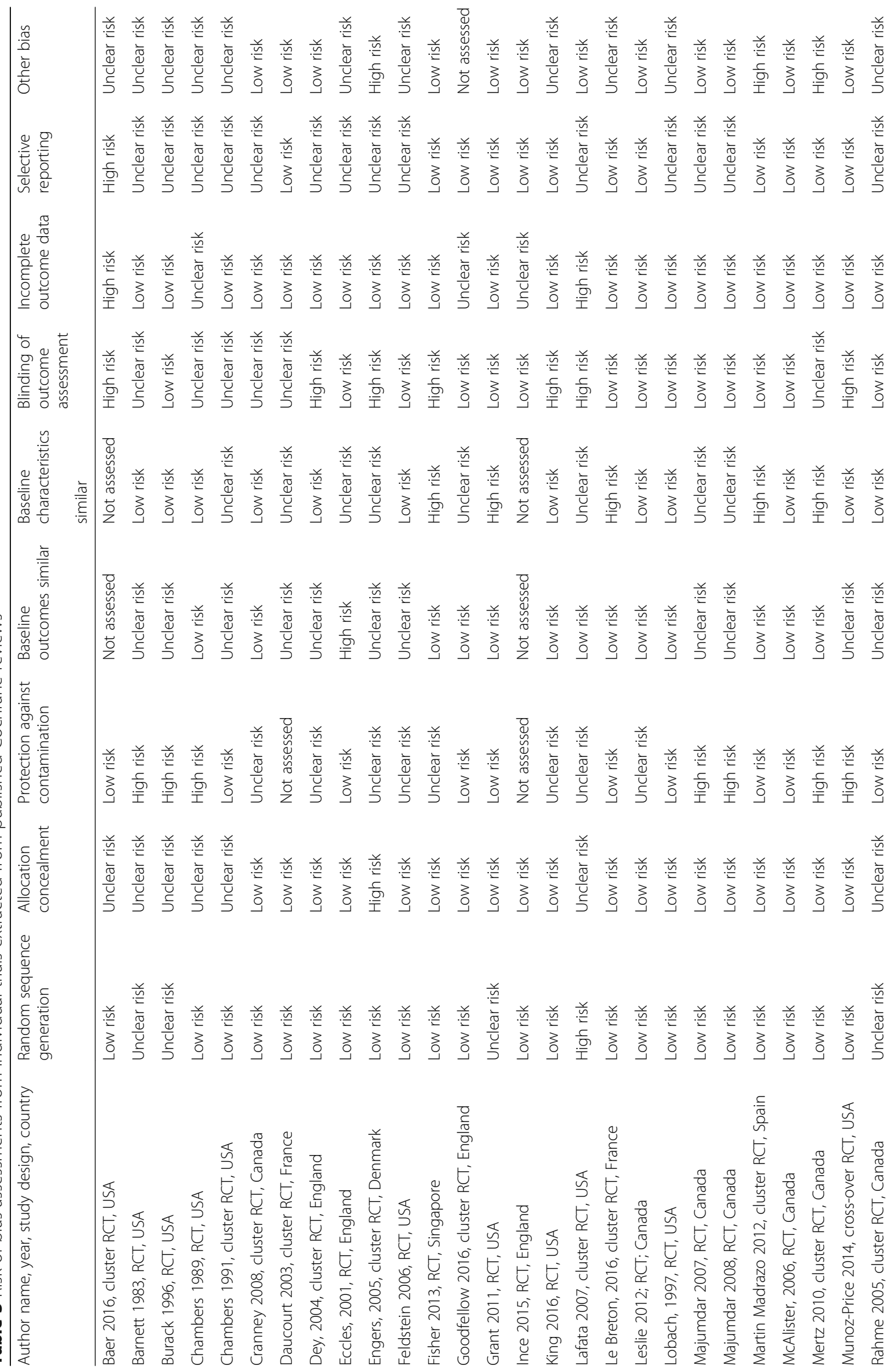




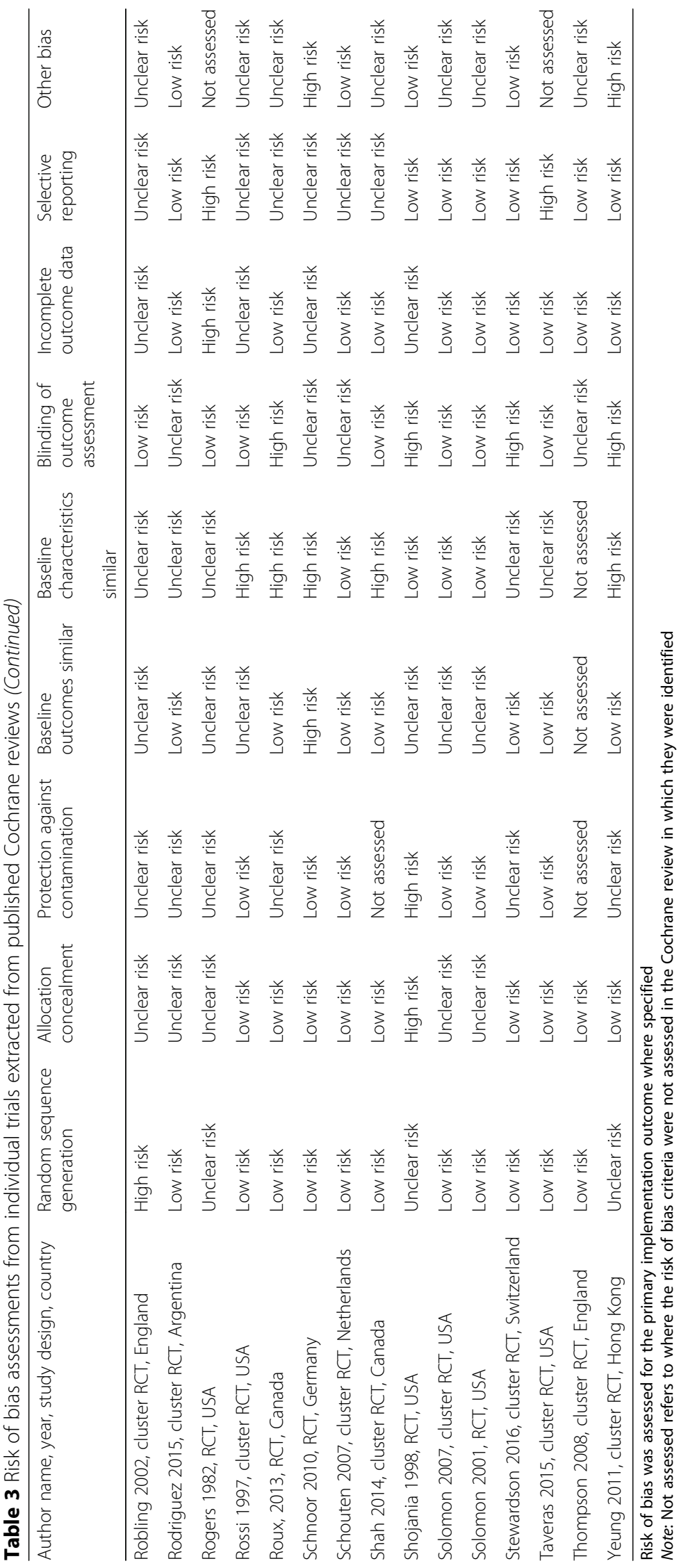


Table 4 Summary of application of nudge strategies in 42 randomised controlled trials included in this study

\begin{tabular}{|c|c|c|}
\hline Nudge strategy & Application in RCTs included in this review & Number $(n, \%)$ \\
\hline Priming nudge & $\begin{array}{l}\text { Stickers displayed at point of care, displaying problematic scans to primary care providers } \\
\text { when high risk patients presents, treatment reminders/flags on online records, visual prime } \\
\text { (picture/smells) to prompt targeted behaviour, reminder posters in display area, } \\
\text { story board with priority problems and endorsement visually displayed, availability } \\
\text { of resources to prime targeted behaviour (pocket hand rub, ball pen, posters), } \\
\text { pocket-sized cards/laminated messages, mailing of questions regarding targeted } \\
\text { behaviour to prime thinking of action, point-of-care prompts to assess/screen, } \\
\text { reminders to measure/assess in electronic medical records at point of care }\end{array}$ & $29,69 \%$ \\
\hline Norms and messenger nudge & $\begin{array}{l}\text { Sending guidelines by email/mail endorsed by a reputable organisation (e.g. chair, } \\
\text { president or governing organisation), presenting information on performance } \\
\text { relative to other providers and units in the area, letters signed by opinion leaders, } \\
\text { resources endorsed by directors of the unit }\end{array}$ & $17,40 \%$ \\
\hline Salience/affect/affect nudge & $\begin{array}{l}\text { Presenting vignettes with relevant patients' cases to physicians, personal consequences } \\
\text { signs }\end{array}$ & $8,19 \%$ \\
\hline Default nudge & Restricting options where not relevant to a particular patient/case (shading of boxes) & $1,2.4 \%$ \\
\hline Commitment/ego nudge & $\begin{array}{l}\text { Providers to publicly declare their commitment/ ego to reducing inappropriate } \\
\text { implementation behaviour/conducting implementation behaviour, displaying } \\
\text { participation in improvement initiatives publicly }\end{array}$ & $1,2.4 \%$ \\
\hline Incentives nudge & Provision of continuing medical education points, certificates & $3,7.0 \%$ \\
\hline
\end{tabular}

development points $[125,128,129]$ to primary care physicians to increase appropriate prescribing or test ordering.

\section{Impact of nudge strategies on healthcare provider behaviour}

Of the 57 outcomes assessed, 49 (86\%) had an estimated effect on clinician behaviour in the hypothesised direction, of which 30 (53\%) did not contain the null value (see Table 5). Figure 2 shows the distribution of studies by whether they had an estimated effect on the outcome. The median standardised mean difference across all continuous outcomes was 0.39 (IQ1 = 0.22, IQ3 = 0.45). For dichotomous outcomes, the median OR across all outcomes was $1.62(\mathrm{IQ} 1=1.13$, IQ3 = 2.76).

When the nudge strategy was included as part of a multicomponent intervention, 24 out of $30(80 \%)$ had a calculated effect estimate that was in the hypothesised direction, of which 15 (50\%) did not contain the null. Comparatively, 20 studies across 27 outcomes tested a nudge only intervention where 25 of these outcomes (93\%) were in the hypothesised direction and 15 (56\%) did not contain the null (see Table 5, Fig. 1).

Twenty-nine studies across 42 outcomes included only one type of nudge strategy as part of their intervention packages. Of this, 36 (86\%) were in the hypothesised

Table 5 A summary of the number and percentage of outcomes reporting an estimated effect in support of the intervention by number of nudge strategies and intervention type

\begin{tabular}{|c|c|c|c|c|}
\hline Strategy & $\begin{array}{l}\text { Number of } \\
\text { studies }\end{array}$ & $\begin{array}{l}\text { Number of } \\
\text { outcomes }\end{array}$ & $\begin{array}{l}\text { Number (\%) of estimated } \\
\text { effects in direction of } \\
\text { hypothesised effect }^{a}\end{array}$ & $\begin{array}{l}\text { Number (\%) estimated effects } \\
\text { in direction of hypothesised } \\
\text { effect and significant }^{\text {a }}\end{array}$ \\
\hline All studies & 42 & 57 & $49(86)$ & $30(53)$ \\
\hline Nudge as part of multicomponent intervention & 22 & 30 & $24(80)$ & $15(50)$ \\
\hline Nudge only intervention & 20 & 27 & $25(93)$ & $15(56)$ \\
\hline One nudge strategy included & 29 & 42 & $36(86)$ & $23(55)$ \\
\hline More than one nudge strategy included & 13 & 15 & $13(87)$ & $7(47)$ \\
\hline \multicolumn{5}{|l|}{ Type of nudge strategies: } \\
\hline Priming & 29 & 41 & $37(90)$ & $24(59)$ \\
\hline Norms and messenger & 17 & 19 & $16(84)$ & $9(47)$ \\
\hline Salience/ affect/affect & 8 & 11 & $8(73)$ & $3(27)$ \\
\hline Incentive & 3 & 3 & $1(33)$ & $0(0)$ \\
\hline Default & 1 & 1 & $1(100)$ & 1 (100) \\
\hline Commitment/ego & 1 & 1 & $1(100)$ & $0(0)$ \\
\hline
\end{tabular}




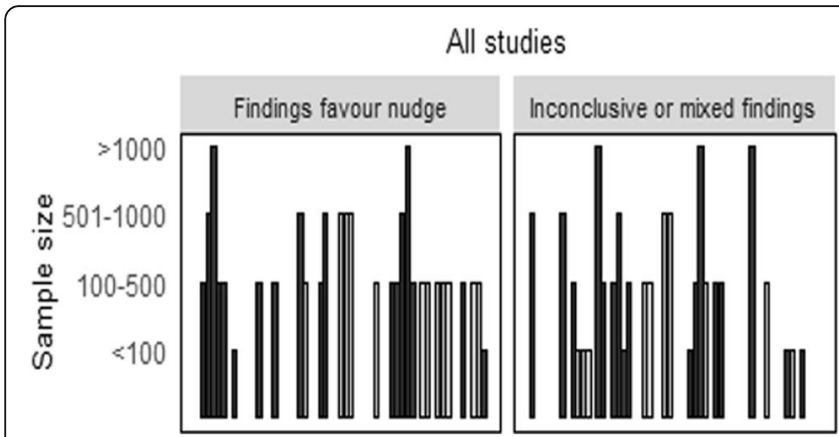

Fig. 2 Harvest plot of estimated effect estimates for all include studies

direction, of which 23 (55\%) did not contain the null. Comparatively, 13 studies across 15 outcomes employed intervention packages that included more than one nudge strategy. Of these, 13 of the 15 outcomes (87\%) were in the hypothesised direction and 7 (47\%) did not contain the null. See Table 5 and Fig. 3 for the number and percentage of outcomes by nudge strategies. Interventions that included a priming nudge showed the most promise, with 37 out of the 41 outcomes $(90 \%)$ in the hypothesised direction.

The most consistent evidence of effect was observed for behaviours such as handwashing (all outcomes in the hypothesised direction, with $70 \%$ containing the null)
$[95,97,101,102,107,112,115,122,130]$, and test ordering and prescribing for management of osteoporosis (all outcomes in the hypothesised direction, with $80 \%$ containing the null) $[108,110,111,117,126]$. The effects were least consistent for obesity management (two out of four in the hypothesised direction, with $25 \%$ containing the null) $[90,96,124]$.

\section{Discussion}

This review of 42 RCTs included within eligible Cochrane systematic reviews found that a variety of nudge strategies have been employed in trials of clinical practice change interventions. For the majority of
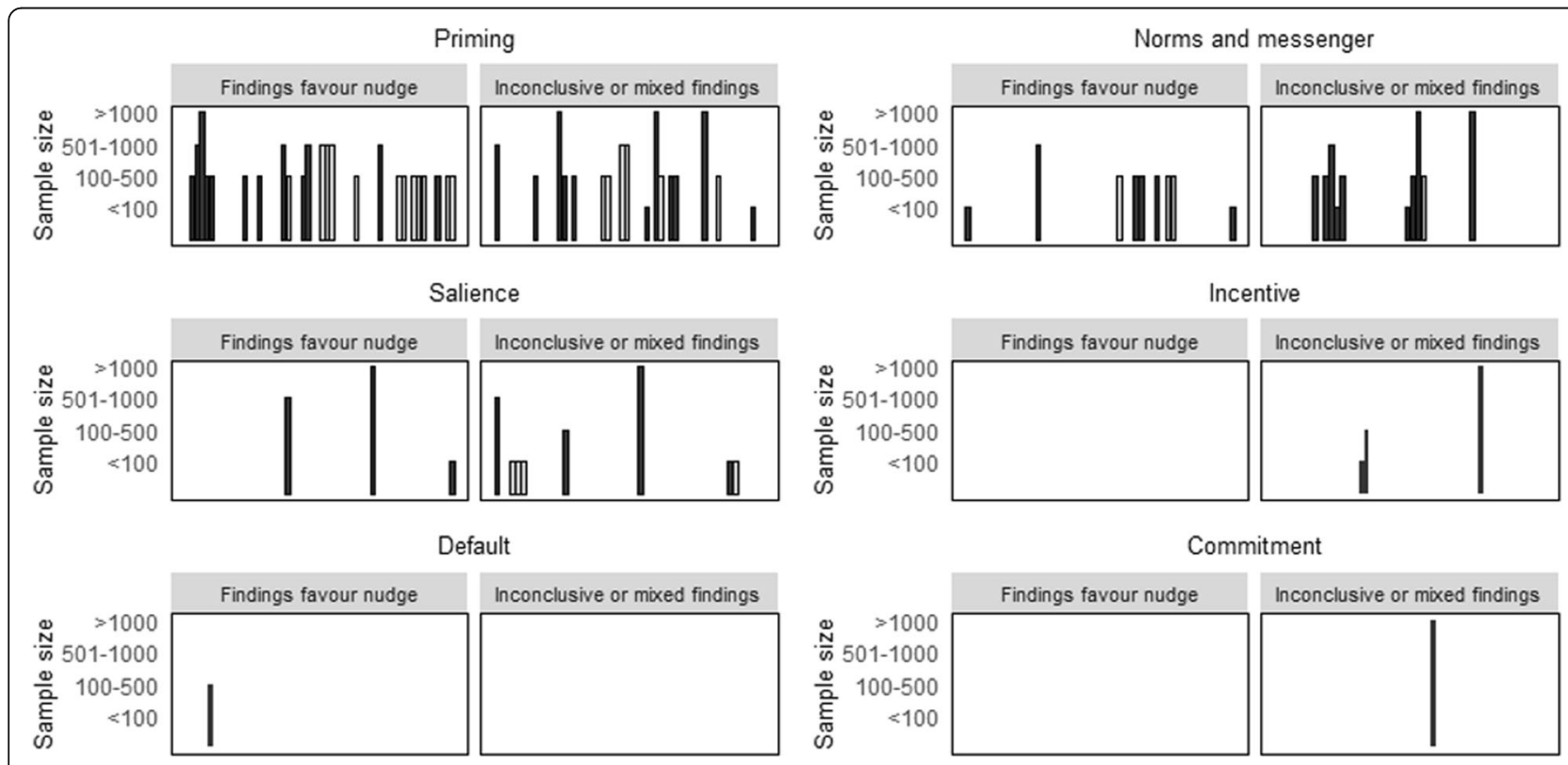

\begin{tabular}{ll|}
\hline Key: Multicomponent intervention & No $\square$ Yes \\
Note: Columns represent indivdual studies & \\
\hline
\end{tabular}

Fig. 3 Harvest plot of estimated effect estimates by nudge classification and whether studies were multi or single component studies 
outcomes assessed (49/57), the effects were in the hypothesised beneficial direction. Additionally, a median effect size of 0.39 (IQ1 $=0.22$, IQ3 $=0.45$ ) for continuous and OR $1.62(95 \% \mathrm{CI}=1.13,=2.76)$ for dichotomous outcomes were calculated. These effects are comparable to other systematic reviews that have assessed the impact of a diverse range of implementation strategies on provider adherence to clinical guidelines $[134,135]$ and support the continued application of nudge interventions in practice. These comparable effects highlight the need to better consider and account for the potential impact of nudge strategies in the evaluation of complex implementation interventions, as these strategies are often overlooked.

Additionally, using vote-counting approaches, our study found that the effects of interventions were not related to the number of nudge strategies employed, or whether nudge strategies were part of a broader package of implementation support. While the evidence around this is mixed, these findings are consistent with a previous review of 25 reviews of implementation strategies, which found no compelling evidence that multicomponent strategies are more effective than single interventions [136]. As our findings relied on indirect comparisons, future studies testing the effects of nudge strategies using staggered or factorial trial designs are needed to better quantify the impact of individual nudge strategies by itself and in combination with other strategies.

Priming nudges were the most frequently evaluated, while few studies assessed the impact of incentive, commitment and ego nudges. While there were variable effects depending on outcomes, the most consistent effect was observed for handwashing, and test ordering and prescribing for osteoporosis management. It is possible that behaviours such as handwashing are more likely to be habitual, where practices are standardised and relatively simple to implement [137], and thus may respond to lower intensity stimuli. The outcomes measured for these behaviours are also likely to be more proximal and directly related to the intervention. These findings highlight the need to carefully consider the target behaviour and outcomes assessed when developing nudge interventions. Further, grounding the design and evaluation of nudge interventions in theory is needed to increase understanding of the context, type of behaviours and for whom nudge interventions may be effective for. Critically, future examination of the impact of nudge interventions according to different sociocultural characteristics (i.e. ethnicity, age, socioeconomic status) is needed to ensure such interventions do not exacerbate health inequalities.

Collectively, findings from this review highlight the positive effects of nudge interventions more broadly and support its application in clinical practice for some behaviours. It also identifies potential areas for development and testing of nudge strategies that have not been well studied such as for commitment nudges, where promising intervention effects have been reported [14]. For healthcare administrators, there is significant opportunity to embed priming, salience and default nudges within existing electronic systems or existing quality improvement tools such as reminders and audit and feedback. For example, scans or test results can be programmed to automatically pop up on electronic health records when a high-risk patient presents for care to facilitate follow-up. Additionally, electronic systems can be programmed to default to a more efficient treatment option where available (i.e. prescribing generic over brand name medications).

Where there is available infrastructure, embedding 'nudge units' similar to that described by Patel et al., within health services provides an innovative way of improving quality of care, while systematically developing and testing the impact of nudge interventions [138]. These units involve collaboration between health system administrators and leaders, front-line staff and researchers. Such collaborations enable the codevelopment of nudge solutions to address identified areas of suboptimal care. The unit is also then involved in subsequent implementation, evaluation and translation of the strategy, if shown to be effective [138]. The embedding of such units within clinical health services is similar to that previously described in public health practice [139] and provides significant opportunity to understand how nudge strategies can be best applied to improve clinical practice. Further, participation in innovative platforms such as the audit and feedback metalab [140], which involves collaboration between healthcare organisations and researchers, can provide an opportunity to further undertake head-to-head comparisons of nudge strategies applied within audit and feedback interventions.

Despite its promise, the application of nudge strategies into practice will firstly need to carefully consider issues around ethics and personal choice. As nudge interventions are inherently designed to influence the automatic systems, these attempts to change behaviour may be seen as challenging the role responsibility of clinicians and perceived as manipulative. Engaging clinicians early on with designing and implementing interventions is crucial to ensure the issues surrounding consent and freedom of choice are given due attention [12, 141].

Findings from this review should be considered in the context of a number of limitations. As there is no general consensus on the kinds of behavioural interventions that are classified as nudge, we used a pragmatic and systematic approach where we searched trials included 
in recently published Cochrane Reviews. This approach was selected as we sought to identify and characterise nudge implementation strategies across a range of medical disciplines and health conditions. As such, our approach undoubtedly failed to capture all eligible published trials, and findings described here are reflective of RCTs included in the published reviews. Future attempts to develop a more targeted electronic search strategy are likely to result in a more comprehensive review. The heterogeneity of outcomes, strategies and targeted guidelines precluded the use of meta-analysis to describe effects. We used non-meta-analytic methods of synthesis including providing a summary of overall effect estimate and vote-counting approaches. Vote-counting approaches are limited in its ability to examine intervention effectiveness as it is unable to account for differential weights in each study based on sample size. Further, seven studies had more than one primary outcome and were included more than once in the vote-counting procedure, which may have given more weight to such studies. While we attempted to extract risk of bias assessments for implementation outcomes, not all reviews specified this. As such, it is possible that the risk of bias assessment for these studies may be related to other non-implementation outcomes.

While such limitations exist, this review included 42 RCTs which provides a broad understanding of how nudge strategies have been applied to improve clinical practice and opportunities to further develop this important area of research. We used the Mindspace framework to provide a broad overview of the types of nudge intervention. To provide more insight into how nudge interventions can change behaviour, future reviews should consider using taxonomies such as the behaviour change techniques to classify these interventions by its psychological targets [142], or mapping to existing implementation taxonomies such as the Expert Recommendations for Implementing Change (ERIC) or EPOC taxonomy [143]. Our review also primarily focused on assessing the impact of the interventions on fidelity outcomes. Future reviews should consider assessing a broader range of implementation outcomes as specified by Proctor et al [144].

\section{Conclusions}

\section{Main conclusion}

This study is the first of its kind and offers new information for policy makers, practitioners and quality improvement agencies to support the application of nudge strategies to improve provision of clinical care. The review provides an overview on how such strategies have been applied and some evidence demonstrating the positive effects of nudge strategies. While more definitive research is needed, the results of this review suggest that nudges could be an effective tool to improve implementation of some clinical guidelines.

\section{Future research}

In addition to primary research exploring the effects of nudge interventions on clinical practice, there is considerable need to develop standard terminology that is applied consistently to describe these strategies as well as detailed guidance on describing such interventions. Currently, the diversity and inconsistency in the terminology represents a real barrier to synthesising, applying and advancing the field. Such work could be considered a priority in the field of implementation science given the considerable research investment and abundance of randomised trials assessing the effects of strategies target rational clinical decision-making.

\section{Supplementary information}

Supplementary information accompanies this paper at https://doi.org/10. 1186/s13012-020-01011-0.

Additional file 1. Estimated effect estimates for continuous data used to generate results

Additional file 2. Estimate effect estimates for dichotomous data used to generate results

\section{Abbreviations}

RCT: Randomised controlled trial; MINDSPACE: Messenger, Incentives, Norms, Defaults, Salience, Priming, Affect, Commitments, Ego; OR: Odds ratios;

EPOC: Cochrane Effective Practice and Organisation of Care; BCTT: Behaviour Change Technique Taxonomy; ERIC: Expert Recommendations for Implementing Change

\section{Acknowledgements}

The authors wish to acknowledge Li Kheng Chai, Beatrice Murawski, Hannah Lamont, Jannah Jones and Melanie Lum for their support with data extraction and manuscript preparation.

\section{Authors' contributions}

SY conceived the idea for the review and drafted the first version of the manuscript. SY, FS, AH, AG, RW and LW contributed to the drafting of the manuscript. SY, FS, AH, RS, NN and AA undertook the data extraction and classification of nudge strategies. AH provided statistical advice and undertook the statistical analyses for the review. All authors reviewed and approved the final manuscript for submission. The corresponding author attests that all listed authors meet authorship criteria and that no others meeting the criteria have been omitted.

\section{Funding}

This project was funded by internal research funds provided to SLY by the School of Medicine and Public Health, University of Newcastle. Hunter New England Population Health, the University of Newcastle, and Hunter Medical Research Institute provided infrastructure support. SLY is a postdoctoral research fellow funded by an Australian Research Council Discovery Early Career Researcher Award (DE170100382). LW is a Hunter New England Clinical Research Fellow and is supported by a National Health and Medical Research Council (NHMRC) Career Development Fellowship (1128348) and Heart Foundation Future Leader Fellowship (101175). RS is supported by a NHMRC TRIP Fellowship (APP1150661). RW is a postdoctoral research fellow funded by the National Heart Foundation (102156). The funders had no involvement in the conception and design of the study. 


\section{Availability of data and materials}

The datasets supporting the conclusions of this article are included within the article (and its additional files).

\section{Ethics approval and consent to participate}

As this is a review of previously published articles, no ethics approval was required for this study.

\section{Consent for publication}

Not applicable

\section{Competing interests}

The authors declare that they have no competing interests.

\section{Author details}

'Hunter New England Population Health, University of Newcastle, Locked Bag 10, Wallsend, New South Wales 2287, Australia. ${ }^{2}$ School of Medicine and Public Health, The University of Newcastle, Callaghan, New South Wales 2308, Australia. ${ }^{3}$ Hunter Medical Research Institute, Newcastle, New South Wales 2300, Australia. ${ }^{4}$ Priority Research Centre for Health Behaviour, The University of Newcastle, Callaghan, New South Wales 2308, Australia.

Received: 4 February 2020 Accepted: 16 June 2020

Published online: 01 July 2020

\section{References}

1. Grimshaw J, Russell I. Effect of clinical guidelines on medical practice: a systematic review of rigorous evaluations. Lancet. 1993;342(8883):1317-22.

2. Mickan S, Burls A, Glasziou P. Patterns of 'leakage' in the utilisation of clinical guidelines: a systematic review. Postgrad Med J. 2011;87(1032):670-9. https://doi.org/10.1136/pgmj.2010.116012.

3. Cochrane Effective Practice and Organisation of Care: EPOC reviews. https:// epoc.cochrane.org/epoc-reviews (2020). Accessed 20/04/2020 2020.

4. Lau R, Stevenson F, Ong BN, Dziedzic K, Treweek S, Eldridge S, et al. Achieving change in primary care--causes of the evidence to practice gap: systematic reviews of reviews. Implementation science : IS. 2016;11:40. https://doi.org/10.1186/s13012-016-0396-4

5. Potthoff S, Rasul O, Sniehotta F, Marques M, Beyer F, Thomson R, et al. The relationship between habit and healthcare professional behaviour in clinical practice: a systematic review and meta-analysis. Health Psychol Rev. 2019; 13(1):73-90. https://doi.org/10.1080/17437199.2018.1547119.

6. Evans JS. Dual-processing accounts of reasoning, judgment, and social cognition. Annu Rev Psychol. 2008:59:255-78. https://doi.org/10.1146/ annurev.psych.59.103006.093629.

7. Presseau J, Johnston M, Heponiemi T, Elovainio M, Francis J, Eccles M, et al. Reflective and automatic processes in health care professional behaviour: a dual process model tested across multiple behaviours. Ann Behav Med. 2014:48(3):347-58.

8. Potthoff S, Presseau J, Sniehotta FF, Johnston M, Elovainio M, Avery L. Planning to be routine: habit as a mediator of the planning-behaviour relationship in healthcare professionals. Implementation science : IS. 2017; 12(1):24. https://doi.org/10.1186/s13012-017-0551-6.

9. Hansen P. The definition of nudge and libertarian paternalism: does the hand fit the glove? European Journal of Risk Regulation. 2016;1:155-74.

10. Thaler RH, Sunstein CR, Balz JP. Choice architecture. The behavioral foundations of public policy. Princeton, NJ, US: Princeton University Press; 2013. p. 428-439.

11. Thaler R, Sunstein C. Nudge: improving decisions about health, wealth, and happiness. Yale University Press; 2008

12. Hallsworth M. MINDSPACE: Influencing behaviour through public policy; 2010

13. Sunstein CR. Nudging: a very short guide. J Consum Policy. 2014;37(4):5838. https://doi.org/10.1007/s10603-014-9273-1.

14. Meeker D, Knight T, Friedberg M, Linder J, Goldstein N, Fox C, et al. Nudging guideline-concordant antibiotic prescribing: a randomized clinical trial. JAMA Intern Med. 2014;174(3):425-31. https://doi.org/10.1001/ jamainternmed.2013.14191.

15. Hallsworth M, Chadborn T, Sallis A, Sanders M, Berry D, Greaves F, et al. Provision of social norm feedback to high prescribers of antibiotics in general practice: a pragmatic national randomised controlled trial. Lancet. 2016;387(10029):1743-52. https://doi.org/10.1016/50140-6736(16)00215-4.
16. Moher D, Liberati A, Tetzlaff J, Altman DG, Group P. Preferred reporting items for systematic reviews and meta-analyses: the PRISMA statement. Bmj. 2009;339:b2535. https://doi.org/10.1136/bmj.b2535.

17. Cochrane Effective Practice and Organisation of Care Group.: Cochrane Effective Practice and Organisation of Care. https://epoc.cochrane.org/ about-us (2019). Accessed 12th July 2019.

18. Curran GM, Bauer M, Mittman B, Pyne JM, Stetler C. Effectivenessimplementation hybrid designs: combining elements of clinical effectiveness and implementation research to enhance public health impact. Med Care. 2012;50(3):217-26. https://doi.org/10.1097/MLR. ob013e3182408812.

19. Centers for Disease Control and Prevention NCflaRDN: interim guidance for infection control within healthcare settings when caring for confirmed cases, probable cases, and cases under investigation for infection with novel influenza A viruses associated with severe disease. https://www.cdc.gov/flu/ avianflu/novel-flu-infection-control.htm (2014). Accessed 8th July 2019.

20. Vlaev I, King D, Dolan P, Darzi A. The theory and practice of "nudging": changing health behaviors. Public Adm Rev. 2016;76(4):550-61.

21. Münscher R, Vetter M, Scheuerle T. A review and taxonomy of choice architecture techniques. J Behav Decis Mak. 2016;29(5):511-24. https://doi. org/10.1002/bdm.1897.

22. Mollenkamp M, Zeppernick M, Schreyogg J. The effectiveness of nudges in improving the self-management of patients with chronic diseases: a systematic literature review. Health Policy. 2019;123(12):1199-209. https:// doi.org/10.1016/j.healthpol.2019.09.008.

23. Wolfenden L, Goldman S, Stacey F, Grady A, Kingsland M, Williams C, et al. Strategies to improve the implementation of workplace-based policies or practices targeting tobacco, alcohol, diet, physical activity and obesity. Cochrane Database Syst Rev. 2018;11. https://doi.org/10.1002/14651858. CD012439.pub2

24. Wolfenden L, Nathan N, Sutherland R, Yoong SL, Hodder R, Wyse R, et al. Strategies for enhancing the implementation of school-based policies or practices targeting risk factors for chronic disease. Cochrane Database Syst Rev. 2017;11. https://doi.org/10.1002/14651858.CD011677.pub2.

25. Higgins JPT TJ, Chandler J, Cumpston M, Li T, Page MJ, Welch VA,. Cochrane Handbook for Systematic Reviews of Interventions version 6.0. www. training.cochrane.org/handbook (2019). Accessed 20/04/2020 2020.

26. Arno $A$, Thomas $S$. The efficacy of nudge theory strategies in influencing adult dietary behaviour: a systematic review and meta-analysis. BMC Public Health. 2016;16(1):676. https://doi.org/10.1186/s12889-016-3272-x.

27. Rossi R, Every N. A computerized intervention to decrease the use of calcium channel blockers in hypertension. J Gen Intern Med. 1997;12:672-8.

28. Borenstein $M$, Hedges $L$, Higgins J, Rothstein $\mathrm{H}$. Introduction to metaanalysis. Chichester: John Wiley \& Sons. Ltd; 2009.

29. Ogilvie D, Fayter D, Petticrew M, Sowden A, Thomas S, Whitehead M, et al. The harvest plot: a method for synthesising evidence about the differential effects of interventions. BMC Med Res Methodol. 2008;8(1):8. https://doi.org/ 10.1186/1471-2288-8-8

30. SAS Institute Inc. SAS software. 9.4 ed. Cary, NC, USA.: SAS Institute Inc; 2014

31. StataCorp. Stata Statistical Software: Release 13.13 ed. College Station, TX: StataCorp LP: 2013.

32. R Core Team. R: a language and environment for statistical computing. Vienna, Austria: R Foundation for Statistical Computing: 2017.

33. Higgins J, Green S. Cochrane Handbook for Systematic Reviews of Interventions Version 5.10 [updated March 2011]. The Cochrane Collaboration; 2011

34. Eamer G, Taheri A, Chen SS, Daviduck Q, Chambers T, Shi X, et al. Comprehensive geriatric assessment for older people admitted to a surgical service. The Cochrane database of systematic reviews. 2018;1:CD012485. https://doi.org/10.1002/14651858.CD012485.pub2.

35. Vaona A, Banzi R, Kwag KH, Rigon G, Cereda D, Pecoraro V, et al. E-learning for health professionals. The Cochrane database of systematic reviews. 2018; 1:CD011736. https://doi.org/10.1002/14651858.CD011736.pub2.

36. Gonçalves-Bradley DC, Buckley BS, Fønhus MS, Glenton C, Henschke N, Lewin $\mathrm{S}$, et al. Mobile-based technologies to support healthcare provider to healthcare provider communication and management of care. Cochrane Database Syst Rev. 2018. https://doi.org/10.1002/14651858.cd012927.

37. Jacobson Vann JC, Jacobson RM, Coyne-Beasley T, Asafu-Adjei JK, Szilagyi PG. Patient reminder and recall interventions to improve immunization rates. The Cochrane database of systematic reviews. 2018;1:CD003941. https://doi.org/10.1002/14651858.CD003941.pub3. 
38. Zaugg V, Korb-Savoldelli V, Durieux P, Sabatier B. Providing physicians with feedback on medication adherence for people with chronic diseases taking long-term medication. The Cochrane database of systematic reviews. 2018; 1:CD012042. https://doi.org/10.1002/14651858.CD012042.pub2.

39. Khalil H, Bell B, Chambers $H$, Sheikh A, Avery AJ. Professional, structural and organisational interventions in primary care for reducing medication errors. The Cochrane database of systematic reviews. 2017;10:CD003942. https:// doi.org/10.1002/14651858.CD003942.pub3.

40. Ciapponi A, Lewin S, Herrera CA, Opiyo N, Pantoja T, Paulsen E, et al. Delivery arrangements for health systems in low-income countries: an overview of systematic reviews. The Cochrane database of systematic reviews. 2017;9:CD011083. https://doi.org/10.1002/14651858.CD01 1083.pub2.

41. Herrera CA, Lewin S, Paulsen E, Ciapponi A, Opiyo N, Pantoja T, et al. Governance arrangements for health systems in low-income countries: an overview of systematic reviews. The Cochrane database of systematic reviews. 2017;9:CD011085. https://doi.org/10.1002/14651858.CD011085.pub2.

42. Pantoja T, Opiyo N, Lewin S, Paulsen E, Ciapponi A, Wiysonge CS, et al. Implementation strategies for health systems in low-income countries: an overview of systematic reviews. The Cochrane database of systematic reviews. 2017;9:CD011086. https://doi.org/10.1002/14651858.CD011086.pub2.

43. Ellis $\mathrm{G}$, Gardner M, Tsiachristas A, Langhorne $\mathrm{P}$, Burke $\mathrm{O}$, Harwood RH, et al, Comprehensive geriatric assessment for older adults admitted to hospital. The Cochrane database of systematic reviews. 2017;9:CD006211. https://doi. org/10.1002/14651858.CD006211.pub3.

44. Wiysonge CS, Paulsen E, Lewin S, Ciapponi A, Herrera CA, Opiyo N, et al. Financial arrangements for health systems in low-income countries: an overview of systematic reviews. The Cochrane database of systematic reviews. 2017;9:CD011084. https://doi.org/10.1002/14651858.CD011084.pub2.

45. Goncalves-Bradley DC, lliffe S, Doll HA, Broad J, Gladman J, Langhorne P, et al. Early discharge hospital at home. The Cochrane database of systematic reviews. 2017;6:CD000356. https://doi.org/10.1002/14651858. CD000356.pub4.

46. Reeves S, Pelone F, Harrison R, Goldman J, Zwarenstein M. Interprofessional collaboration to improve professional practice and healthcare outcomes. The Cochrane database of systematic reviews. 2017;6:CD000072. https://doi. org/10.1002/14651858.CD000072.pub3.

47. Archambault PM, van de Belt TH, Kuziemsky C, Plaisance A, Dupuis A, McGinn CA, et al. Collaborative writing applications in healthcare: effects on professional practice and healthcare outcomes. The Cochrane database of systematic reviews. 2017;5:CD011388. https://doi.org/10.1002/14651858. CD011388.pub2

48. Young C, Hall AM, Goncalves-Bradley DC, Quinn TJ, Hooft L, van Munster $\mathrm{BC}$, et al. Home or foster home care versus institutional long-term care for functionally dependent older people. The Cochrane database of systematic reviews. 2017:4:CD009844. https://doi.org/10.1002/14651858.CD009844.pub2.

49. Yuan B, He L, Meng Q, Jia L. Payment methods for outpatient care facilities. The Cochrane database of systematic reviews. 2017;3:CD011153. https://doi. org/10.1002/14651858.CD011153.pub2.

50. Smith SM, Cousins G, Clyne B, Allwright S, O'Dowd T. Shared care across the interface between primary and specialty care in management of long term conditions. The Cochrane database of systematic reviews. 2017;2:CD004910. https://doi.org/10.1002/14651858.CD004910.pub3.

51. Chen $\mathrm{CE}$, Chen $\mathrm{CT}, \mathrm{Hu}$ J, Mehrotra A. Walk-in clinics versus physician offices and emergency rooms for urgent care and chronic disease management. The Cochrane database of systematic reviews. 2017;2:CD011774. https://doi. org/10.1002/14651858.CD011774.pub2.

52. Vaona A, Pappas Y, Grewal RS, Ajaz M, Majeed A, Car J. Training interventions for improving telephone consultation skills in clinicians. The Cochrane database of systematic reviews. 2017;1:CD010034. https://doi.org/ 10.1002/14651858.CD010034.pub2.

53. Flodgren G, Goncalves-Bradley DC, Pomey MP. External inspection of compliance with standards for improved healthcare outcomes. The Cochrane database of systematic reviews. 2016;12:CD008992. https://doi. org/10.1002/14651858.CD008992.pub3.

54. Weeks G, George J, Maclure K, Stewart D. Non-medical prescribing versus medical prescribing for acute and chronic disease management in primary and secondary care. The Cochrane database of systematic reviews. 2016;11: CD011227. https://doi.org/10.1002/14651858.CD011227.pub2.

55. Shepperd S, lliffe S, Doll HA, Clarke MJ, Kalra L, Wilson AD, et al. Admission avoidance hospital at home. The Cochrane database of systematic reviews. 2016:9:CD007491. https://doi.org/10.1002/14651858.CD007491.pub2.
56. Wilson AD, Childs S, Goncalves-Bradley DC, Irving GJ. Interventions to increase or decrease the length of primary care physicians' consultation. The Cochrane database of systematic reviews. 2016;8:CD003540. https://doi. org/10.1002/14651858.CD003540.pub3.

57. Gaitonde R, Oxman AD, Okebukola PO, Rada G. Interventions to reduce corruption in the health sector. The Cochrane database of systematic reviews. 2016;8:CD008856. https://doi.org/10.1002/14651858.CD008856.pub2.

58. Abdel-Aleem H, El-Gibaly OM, El-Gazzar AF, Al-Attar GS. Mobile clinics for women's and children's health. The Cochrane database of systematic reviews. 2016;8:CD009677. https://doi.org/10.1002/14651858.CD009677.pub2.

59. Wiysonge CS, Abdullahi LH, Ndze VN, Hussey GD. Public stewardship of private for-profit healthcare providers in low- and middle-income countries. The Cochrane database of systematic reviews. 2016;8:CD009855. https://doi. org/10.1002/14651858.CD009855.pub2.

60. Oyo-lta A, Wiysonge CS, Oringanje C, Nwachukwu CE, Oduwole O, Meremikwu MM. Interventions for improving coverage of childhood immunisation in lowand middle-income countries. The Cochrane database of systematic reviews. 2016;7:CD008145. https://doi.org/10.1002/14651858.CD008145.pub3.

61. Gera T, Shah D, Garner P, Richardson M, Sachdev HS. Integrated management of childhood illness (IMCI) strategy for children under five. The Cochrane database of systematic reviews. 2016;6:CD010123. https://doi. org/10.1002/14651858.CD010123.pub2.

62. Campbell F, Biggs K, Aldiss SK, O'Neill PM, Clowes M, McDonagh J, et al. Transition of care for adolescents from paediatric services to adult health services. The Cochrane database of systematic reviews. 2016;4:CD009794. https://doi.org/10.1002/14651858.CD009794.pub2.

63. Balogh R, McMorris CA, Lunsky Y, Ouellette-Kuntz H, Bourne L, Colantonio A, et al. Organising healthcare services for persons with an intellectual disability. The Cochrane database of systematic reviews. 2016;4:CD007492. https://doi.org/10.1002/14651858.CD007492.pub2.

64. Smith SM, Wallace E, O'Dowd T, Fortin M. Interventions for improving outcomes in patients with multimorbidity in primary care and community settings. The Cochrane database of systematic reviews. 2016;3:CD006560. https://doi.org/10.1002/14651858.CD006560.pub3.

65. Opiyo N, Yamey G, Garner P. Subsidising artemisinin-based combination therapy in the private retail sector. The Cochrane database of systematic reviews. 2016;3:CD009926. https://doi.org/10.1002/14651858.CD009926.pub2.

66. Christensen M, Lundh A. Medication review in hospitalised patients to reduce morbidity and mortality. The Cochrane database of systematic reviews. 2016;2:CD008986. https://doi.org/10.1002/14651858.CD008986.pub3.

67. Alldred DP, Kennedy MC, Hughes C, Chen TF, Miller P. Interventions to optimise prescribing for older people in care homes. The Cochrane database of systematic reviews. 2016;2:CD009095. https://doi.org/10.1002/ 14651858.CD009095.pub3.

68. Munabi-Babigumira S, Glenton C, Lewin S, Fretheim A, Nabudere H. Factors that influence the provision of intrapartum and postnatal care by skilled birth attendants in low- and middle-income countries: a qualitative evidence synthesis. The Cochrane database of systematic reviews. 2017;11: CD011558. https://doi.org/10.1002/14651858.CD011558.pub2.

69. Tonkin-Crine SK, Tan PS, van Hecke O, Wang K, Roberts NW, McCullough A, et al. Clinician-targeted interventions to influence antibiotic prescribing behaviour for acute respiratory infections in primary care: an overview of systematic reviews. The Cochrane database of systematic reviews. 2017;9: CD012252. https://doi.org/10.1002/14651858.CD012252.pub2.

70. Davey P, Marwick CA, Scott CL, Charani E, McNeil K, Brown E, et al. Interventions to improve antibiotic prescribing practices for hospital inpatients. The Cochrane database of systematic reviews. 2017;2:CD003543. https://doi.org/10.1002/14651858.CD003543.pub4.

71. Gould DJ, Moralejo D, Drey N, Chudleigh JH, Taljaard M. Interventions to improve hand hygiene compliance in patient care. The Cochrane database of systematic reviews. 2017;9:CD005186. https://doi.org/10.1002/14651858. CD005186.pub4.

72. Flodgren G, Goncalves-Bradley DC, Summerbell CD. Interventions to change the behaviour of health professionals and the organisation of care to promote weight reduction in children and adults with overweight or obesity. The Cochrane database of systematic reviews. 2017;11:CD000984. https://doi.org/10.1002/14651858.CD000984.pub3.

73. Tzortziou Brown V, Underwood M, Mohamed N, Westwood O, Morrissey D. Professional interventions for general practitioners on the management of musculoskeletal conditions. The Cochrane database of systematic reviews. 2016:5:CD007495. https://doi.org/10.1002/14651858.CD007495.pub2. 
74. Arditi C, Rege-Walther M, Durieux P, Burnand B. Computer-generated reminders delivered on paper to healthcare professionals: effects on professional practice and healthcare outcomes. The Cochrane database of systematic reviews. 2017;7:CD001175. https://doi.org/10.1002/14651858. CD001175.pub4

75. Flodgren G, Hall AM, Goulding L, Eccles MP, Grimshaw JM, Leng GC, et al. Tools developed and disseminated by guideline producers to promote the uptake of their guidelines. The Cochrane database of systematic reviews. 2016:8:CD010669. https://doi.org/10.1002/14651858.CD010669.pub2.

76. Bighelli I, Ostuzzi G, Girlanda F, Cipriani A, Becker T, Koesters M, et al. Implementation of treatment guidelines for specialist mental health care. The Cochrane database of systematic reviews. 2016;12:CD009780. https:// doi.org/10.1002/14651858.CD009780.pub3.

77. Bishop PB, Wing PC. Knowledge transfer in family physicians managing patients with acute low back pain: a prospective randomized control trial. The spine journal : official journal of the North American Spine Society. 2006;6(3):282-8. https://doi.org/10.1016/j.spinee.2005.10.008

78. Kerry S, Oakeshott P, Dundas D, Williams J. Influence of postal distribution of The Royal College of Radiologists' guidelines, together with feedback on radiological referral rates, on X-ray referrals from general practice: a randomized controlled trial. Fam Pract. 2000;17(1):46-52.

79. Schectman J, Schroth W, Verme D, Voss J. Randomized controlled trial of education and feedback for implementation of guidelines for acute low back pain. J Gen Intern Med. 2003;18:773-80.

80. Stevenson K, Searle K, Curry G, Boyce J, Harbarth S, Stoddard G, et al. Infection control interventions in small rural hospitals with limited resources: results of a cluster-randomized feasibility trial. Antimicrob Resist Infect Control. 2014;3:10. https://doi.org/10.1186/2047-2994-3-10.

81. Tierney W, Hui S, McDonald C. Delayed feedback of physician performance versus immediate reminders to perform preventive care: effects on physician compliance. Med Care. 1986;24(8):659-66.

82. Huis A, Schoonhoven L, Grol R, Donders R, Hulscher M, van Achterberg T. Impact of a team and leaders-directed strategy to improve nurses' adherence to hand hygiene guidelines: a cluster randomised trial. Int J Nurs Stud. 2013;50(4):464-74. https://doi.org/10.1016/j.ijnurstu.2012.08.004.

83. Fuller C, Michie S, Savage J, McAteer J, Besser S, Charlett A, et al. The Feedback Intervention Trial (FIT)--improving hand-hygiene compliance in UK healthcare workers: a stepped wedge cluster randomised controlled trial. PLoS One. 2012;7(10):e41617. https://doi.org/10.1371/journal.pone. 0041617.

84. Gulmezoglu AM, Langer A, Piaggio G, Lumbiganon P, Villar J, Grimshaw J. Cluster randomised trial of an active, multifaceted educational intervention based on the WHO Reproductive Health Library to improve obstetric practices. BJOG : an international journal of obstetrics and gynaecology. 2007;114(1):16-23. https://doi.org/10.1111/j.1471-0528.2006.01091.x.

85. Kritchevsky S, Braun B, Bush A, Bozikis M, Kusek L, Burke J, et al. The effect of a quality improvement collaborative to improve antimicrobial prophylaxis in surgical patients. Ann Intern Med. 2008;149:472-80.

86. Paul $M$, Andreassen $S$, Tacconelli $E$, Nielsen AD, Almanasreh N, Frank U, et al. Improving empirical antibiotic treatment using TREAT, a computerized decision support system: cluster randomized trial. J Antimicrob Chemother. 2006;58(6):1238-45. https://doi.org/10.1093/jac/dkl372.

87. Bekkering GE, Hendriks HJ, van Tulder MW, Knol DL, Hoeijenbos M, Oostendorp RA, et al. Effect on the process of care of an active strategy to implement clinical guidelines on physiotherapy for low back pain: a cluste randomised controlled trial. Quality \& safety in health care. 2005;14(2):10712. https://doi.org/10.1136/qshc.2003.009357.

88. Camins BC, King MD, Wells JB, Googe HL, Patel M, Kourbatova EV, et al. Impact of an antimicrobial utilization programme on antimicrobial use at a large teaching hospital: a randomized controlled trial. Infect Control Hosp Epidemiol. 2009;30(10):931-8. https://doi.org/10.1086/605924.

89. Senn L, Burnand B, Francioli P, Zanetti G. Improving appropriateness of antibiotic therapy: randomized trial of an intervention to foster reassessment of prescription after 3 days. J Antimicrob Chemother. 2004:53:1062-7.

90. Baer HJ, Wee CC, DeVito K, Orav EJ, Frolkis JP, Williams DH, et al. Design of a cluster-randomized trial of electronic health record-based tools to address overweight and obesity in primary care. Clinical trials. 2015;12(4):374-83. https://doi.org/10.1177/1740774515578132.

91. Barnett G, Winickoff R, Morgan M, Zielstorff R. A computer-based monitoring system for follow-up of elevated blood pressure. Med Care. 1983;21(4):400-9.
92. Burack R, Gimotty P, George J, Simon M, Dews P, Moncrease A. The effect of patient and physician reminders on use of screening mammography in a Health Maintenance Organization. Results of a randomized controlled trial. Cancer. 1996;78:1708-21.

93. Chambers C, Balaban D, Carlson B, Ungemack J, Grasberger D. Microcomputer-generated reminders: improving the compliance of primary care physicians with mammography screening guidelines. J Fam Pract. 1989:29:3.

94. Chambers C, Balaban D, Carlson B, Grasberger D. The effect of microcomputer-generated reminders on influenza vaccination rates in a University-based family practice center. J Am Board Fam Pract. 1991;4:19-26.

95. Fisher DA, Seetoh T, Oh May-Lin H, Viswanathan S, Toh Y, Yin WC, et al. Automated measures of hand hygiene compliance among healthcare workers using ultrasound: validation and a randomized controlled trial. Infect Control Hosp Epidemiol. 2013;34(9):919-28. https://doi.org/10.1086/ 671738.

96. Goodfellow J, Agarwal S, Harrad F, Shepherd D, Morris T, Ring A, et al. Cluster randomised trial of a tailored intervention to improve the management of overweight and obesity in primary care in England. Implementation science : IS. 2016;11(1):77. https://doi.org/10.1186/s13012016-0441-3.

97. King D, Vlaev I, Everett-Thomas R, Fitzpatrick M, Darzi A, Birnbach DJ. "Priming" hand hygiene compliance in clinical environments. Health psychology : official journal of the Division of Health Psychology, American Psychological Association. 2016;35(1):96-101. https://doi.org/10.1037/ hea0000239.

98. Lafata JE, Kolk D, Peterson EL, McCarthy BD, Weiss TW, Chen YT, et al. Improving osteoporosis screening: results from a randomized cluster trial. J Gen Intern Med. 2007;22(3):346-51. https://doi.org/10.1007/s11606-0060060-9.

99. Le Breton J, Ferrat E, Attali C, Bercier S, Le Corvoisier P, Brixi Z, et al. Effect of reminders mailed to general practitioners on colorectal cancer screening adherence: a cluster-randomized trial. European journal of cancer prevention : the official journal of the European Cancer Prevention Organisation. 2016;25(5):380-7. https://doi.org/10.1097/CEJ. 0000000000000200

100. Lobach D, Hammond W. Computerized decision support based on a clinical practice guideline improves compliance with care standards. Am J Med. 1997;102:89-98.

101. Martin-Madrazo C, Soto-Diaz S, Canada-Dorado A, Salinero-Fort MA, MedinaFernandez M. Carrillo de Santa Pau E, et al. Cluster randomized trial to evaluate the effect of a multimodal hand hygiene improvement strategy in primary care. Infect Control Hosp Epidemiol. 2012;33(7):681-8. https://doi. org/10.1086/666343.

102. Munoz-Price L, Patel Z, Banks S, Arheart K, Eber S, Lubarsky D, et al. Randomized crossover study evaluating the effect of a hand sanitizer dispenser on the frequency of hand hygiene among anesthesiology staff in the operating room. Infect Control Hosp Epidemiol. 2014;35(6):717-20.

103. Rogers J, Haring OM, Wortman P, Watson R, Goetz J. Medical information systems: assessing impact in the areas of hypertension, obesity and renal disease. Med Care. 1982;1(1):63-74

104. Schnoor M, Meyer T, Suttorp N, Raspe H, Welte T, Schafer T, et al. Development and evaluation of an implementation strategy for the German guideline on community-acquired pneumonia. Quality \& safety in health care. 2010;19(6):498-502. https://doi.org/10.1136/qshc.2008.029629.

105. Shojania K, Yokoe D, Platt R, Fiskio J, Ma'luf N, Bates D. Reducing vancomycin use utilizing a computer guideline: results of a randomized controlled trial. J Am Med Inform Assoc. 1998:5:554-62.

106. Thompson A, Sullivan SA, Barley M, Strange SO, Moore L, Rogers P, et al. The DEBIT trial: an intervention to reduce antipsychotic polypharmacy prescribing in adult psychiatry wards - a cluster randomized controlled trial. Psychol Med. 2008;38(5):705-15. https://doi.org/10.1017/ S003329170700147X

107. Yeung W, Tam W, Wong T. Clustered randomized controlled trial of a hand hygiene intervention involving pocket-sized containers of alcohol-based hand rub for the control of infections in long-term care facilities. Infect Control Hosp Epidemiol. 2011;32(1):67-76.

108. Cranney A, Lam M, Ruhland L, Brison R, Godwin M, Harrison MM, et al. A multifaceted intervention to improve treatment of osteoporosis in postmenopausal women with wrist fractures: a cluster randomized trial. Osteoporosis international : a journal established as result of cooperation 
between the European Foundation for Osteoporosis and the National Osteoporosis Foundation of the USA. 2008;19(12):1733-40. https://doi.org/ 10.1007/s00198-008-0669-0.

109. Engers $A$, Wensing $M$, van Tulder M, Timmermans A, Oostendorp R, Koes B, et al. Implementation of the Dutch Low Back Pain Guideline for General Practitioners. A Cluster Randomized Controlled Trial. Spine. 2005;30:595-600.

110. Feldstein A, Elmer PJ, Smith DH, Herson M, Orwoll E, Chen C, et al. Electronic medical record reminder improves osteoporosis management after a fracture: a randomized, controlled trial. J Am Geriatr Soc. 2006;54(3): 450-7. https://doi.org/10.1111/j.1532-5415.2005.00618.x.

111. Majumdar SR, Johnson JA, McAlister FA, Bellerose D, Russell AS, Hanley DA et al. Multifaceted intervention to improve diagnosis and treatment of osteoporosis in patients with recent wrist fracture: a randomized controlled trial. CMAJ : Canadian Medical Association journal = journal de l'Association medicale canadienne. 2008;178(5):569-75. https://doi.org/10.1503/cmaj. 070981.

112. Mertz D, Dafoe N, Walter S, Brazil K, Loeb M. Effect of a multifaceted intervention on adherence to hand hygiene among healthcare workers: a cluster-randomized trial. Infect Control Hosp Epidemiol. 2010;31(11):1170-6.

113. Shah B, Bhattacharyya O, Yu C, Mamdani M, Parsons J, Straus S, et al. Effect of an educational toolkit on quality of care: a pragmatic cluster randomized trial. PLoS Med. 2014;11:2.

114. Dey P, Simpson C, Collins S, Hodgson G, Dowrick C, Simison A, et al. Implementation of RCGP guidelines for acute low back pain: a cluster randomised controlled trial. Br J Gen Pract. 2004;54:33-7.

115. Grant AM, Hofmann DA. It's not all about me: motivating hand hygiene among health care professionals by focusing on patients. Psychol Sci. 2011; 22(12):1494-9. https://doi.org/10.1177/0956797611419172.

116. Ince $P$, Tai S, Haddock G. Using plain English and behaviourally specific language to increase the implementation of clinical guidelines for psychological treatments in schizophrenia. J Ment Health. 2015;24(3):129-33. https://doi.org/10.3109/09638237.2014.958213.

117. Leslie W, LaBine L, Klassen P, Dreilich D, Caetano P. Closing the gap in postfracture care at the population level: a randomized controlled trial. CMAJ : Canadian Medical Association journal = journal de l'Association medicale canadienne. 2012;184(3):290-6.

118. Daucourt V, Saillour-Glenisson F, Michel P, Jutand M-A, Abouelfath A. A multicenter cluster randomized controlled trial of strategies to improve thyroid function testing. Med Care. 2003;41(3):432-41.

119. Eccles M, Steen N, Grimshaw J, Thomas L, McNamee P, Soutter J, et al. Effect of audit and feedback, and reminder messages on primary-care radiology referrals: a randomised trial. Lancet. 2001;357(9266):1406-9. https://doi.org/10.1016/s0140-6736(00)04564-5.

120. Majumdar SR, Tsuyuki RT, McAlister FA. Impact of opinion leader-endorsed evidence summaries on the quality of prescribing for patients with cardiovascular disease: a randomized controlled trial. Am Heart J. 2007; 153(1):22-e1-8. https://doi.org/10.1016/j.ahj.2006.07.030.

121. McAlister FA, Fradette M, Graham M, Majumdar SR, Ghali WA, Williams R, et al. A randomized trial to assess the impact of opinion leader endorsed evidence summaries on the use of secondary prevention strategies in patients with coronary artery disease: the ESP-CAD trial protocol [NCT00175240]. Implementation science : IS. 2006;1:11. https://doi.org/10. 1186/1748-5908-1-11.

122. Rodriguez V, Giuffre C, Villa S, Almada G, Prasopa-Plaizier N, Gogna M, et al. A multimodal intervention to improve hand hygiene in ICUs in Buenos Aires, Argentina: a stepped wedge trial. International journal for quality in health care : journal of the International Society for Quality in Health Care. 2015;27(5):405-11. https://doi.org/10.1093/intqhc/mzv065.

123. Schouten JA, Hulscher ME, Trap-Liefers J, Akkermans RP, Kullberg BJ, Grol RP, et al. Tailored interventions to improve antibiotic use for lower respiratory tract infections in hospitals: a cluster-randomized, controlled trial. Clinical infectious diseases: an official publication of the Infectious Diseases Society of America. 2007;44(7):931-41. https://doi.org/10.1086/512193.

124. Taveras EM, Marshall R, Kleinman KP, Gillman MW, Hacker K, Horan CM, et al. Comparative effectiveness of childhood obesity interventions in pediatric primary care: a cluster-randomized clinical trial. JAMA Pediatr. 2015;169(6): 535-42. https://doi.org/10.1001/jamapediatrics.2015.0182.

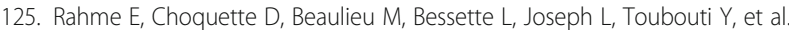
Impact of a general practitioner educational intervention on osteoarthritis treatment in an elderly population. Am J Med. 2005;118(11):1262-70. https://doi.org/10.1016/j.amjmed.2005.03.026.
126. Roux S, Beaulieu M, Beaulieu MC, Cabana F, Boire G. Priming primary care physicians to treat osteoporosis after a fragility fracture: an integrated multidisciplinary approach. J Rheumatol. 2013;40(5):703-11. https://doi.org/ 10.3899/jrheum.120908.

127. Solomon D, Van Houten L, Glynn R, Baden L, Curtis K, Schrager H, et al. Academic detailing to improve use of broad-spectrum antibiotics at an academic medical center. Arch Intern Med. 2001;161:1897-902.

128. Robling M, Houston $H$, Kinnersley $P$, Hourihan $M$, Cohen $D$, Hale J, et al. General Practitioners' use of Magnetic Resonance Imaging: an open randomized trial comparing telephone and written requests and an open randomized controlled trial of different methods of local guideline dissemination. Clin Radiol. 2002;57:402-7.

129. Solomon DH, Katz JN, Finkelstein JS, Polinski JM, Stedman M, Brookhart MA, et al. Osteoporosis improvement: a large-scale randomized controlled trial of patient and primary care physician education. Journal of bone and mineral research : the official journal of the American Society for Bone and Mineral Research. 2007;22(11):1808-15. https://doi.org/10.1359/jbmr.070717.

130. Stewardson AJ, Sax H, Gayet-Ageron A, Touveneau S, Longtin Y, Zingg W, et al. Enhanced performance feedback and patient participation to improve hand hygiene compliance of health care workers in the setting of established multimodal promotion: a single-centre, cluster randomised controlled trial. Lancet Infect Dis. 2016;16(12):1345-55. https://doi.org/10. 1016/s1473-3099(16)30256-0.

131. Majumdar SR, McAlister FA, Tsuyuki RT. A cluster randomized trial to assess the impact of opinion leader endorsed evidence summaries on improving quality of prescribing for patients with chronic cardiovascular disease: rationale and design [ISRCTN26365328]. BMC Cardiovasc Disord. 2005;5(1): 17. https://doi.org/10.1186/1471-2261-5-17.

132. McAlister FA, Fradette M, Majumdar SR, Williams R, Graham M, McMeekin J, et al. The Enhancing Secondary Prevention in Coronary Artery Disease trial. CMAJ: Canadian Medical Association journal = journal de l'Association medicale canadienne. 2009;181(12):897-904. https://doi.org/10.1503/cmaj. 090917.

133. Taveras EM, Gortmaker SL, Hohman KH, Horan CM, Kleinman KP, Mitchell K, et al. Randomized controlled trial to improve primary care to prevent and manage childhood obesity: the High Five for Kids study. Arch Pediatr Adolesc Med. 2011;165(8):714-22. https://doi.org/10.1001/archpediatrics. 2011.44.

134. Tuti T, Nzinga J, Njoroge M, Brown B, Peek N, English M, et al. A systematic review of electronic audit and feedback: intervention effectiveness and use of behaviour change theory. Implementation science : IS. 2017;12(1):61. https://doi.org/10.1186/s13012-017-0590-z.

135. Pedersen ER, Rubenstein L, Kandrack R, Danz M, Belsher B, Motala A, et al. Elusive search for effective provider interventions: a systematic review of provider interventions to increase adherence to evidence-based treatment for depression. Implementation science : IS. 2018;13(1):99. https://doi.org/10. 1186/s13012-018-0788-8.

136. Squires J, Sullivan K, Eccles M, Worswick J, Grimshaw J. Are multifaceted interventions more effective than single-component interventions in changing health-care professionals' behaviours? An overview of systematic reviews. Implement Sci. 2014;9:152.

137. Jumaa PA. Hand hygiene: simple and complex. Int J Infect Dis. 2005;9(1):314. https://doi.org/10.1016/j.ijid.2004.05.005.

138. Patel MS, Volpp KG, Asch DA. Nudge units to improve the delivery of health care. N Engl J Med. 2018;378(3):214-6. https://doi.org/10.1056/NEJMp1712984.

139. Wolfenden L, Yoong SL, Williams CM, Grimshaw J, Durrheim DN, Gillham K, et al. Embedding researchers in health service organizations improves research translation and health service performance: the Australian Hunter New England Population Health example. J Clin Epidemiol. 2017;85:3-11. https://doi.org/10.1016/j.jclinepi.2017.03.007.

140. Grimshaw JM, Ivers N, Linklater S, Foy R, Francis JJ, Gude WT, et al. Reinvigorating stagnant science: implementation laboratories and a metalaboratory to efficiently advance the science of audit and feedback. BMJ Quality \&amp;amp; Safety. 2019;28(5):416. doi: 10.1136/bmjqs-2018-008355.

141. Gorin M, Joffe S, Dickert N, Halpern S. Justifying clinical nudges. Hastings Cent Rep. 2017;47(2):32-8. https://doi.org/10.1002/hast.688.

142. Michie S, Richardson M, Johnston M, Abraham C, Francis J, Hardeman W, et al. The Behavior Change Technique Taxonomy (v1) of 93 hierarchically clustered techniques: building an international consensus for the reporting of behavior change interventions. Ann Behav Med. 2013;46(1):81-95. https:// doi.org/10.1007/s12160-013-9486-6. 
143. Powell BJ, Waltz TJ, Chinman MJ, Damschroder L, Smith JL, Matthieu MM, et al. A refined compilation of implementation strategies: results from the Expert Recommendations for Implementing Change (ERIC) project. Implement Sci. 2015;10(1):21. https://doi.org/10.1186/s13012-015-0209-1.

144. Proctor E, Silmere H, Raghavan R, Hovmand P, Aarons G, Bunger A, et al. Outcomes for implementation research: conceptual distinctions,

measurement challenges, and research agenda. Admin Pol Ment Health. 2011;38(2):65-76. https://doi.org/10.1007/s10488-010-0319-7.

\section{Publisher's Note}

Springer Nature remains neutral with regard to jurisdictional claims in published maps and institutional affiliations.

Ready to submit your research? Choose BMC and benefit from:

- fast, convenient online submission

- thorough peer review by experienced researchers in your field

- rapid publication on acceptance

- support for research data, including large and complex data types

- gold Open Access which fosters wider collaboration and increased citations

- maximum visibility for your research: over $100 \mathrm{M}$ website views per year

At BMC, research is always in progress.

Learn more biomedcentral.com/submissions 